\title{
„Was vor ein prächtiges Ansehen es gegeben ...“ Die Bedeutung visueller Wahrnehmung für die Rezeption von Musik zur repraesentatio majestatis an sächsischen Höfen
}

\author{
von \\ CHRISTIAN AHRENS
}

Im aktuellen interdisziplinären Diskurs über die Zeremonialwissenschaft und die Elemente der repraesentatio majestatis besteht Konsens darüber, dass sich das höfische Zeremoniell nicht nur an „den Fürsten, seine Familie, die Höflinge, die anderen europäischen Fürsten und ihre Diplomaten" richtete, sondern zugleich „an die eigenen Untertanen und an die von auswärts kommenden Fremden, bei denen man sich ,in gutem Ansehen "erhalten " wollte. ${ }^{1}$ Die verschiedenen Aufgabenbereiche des Hofzeremoniells hat Andreas Gestrich folgendermaßen systematisiert: „Das frühneuzeitliche Hofzeremoniell besaß eine dreifache Funktion: Es regulierte das Leben am Hof, es legte die Verkehrsformen zwischen verschiedenen Höfen fest und es stellte den Hof für die eigenen Untertanen dar. Zum einen wurden durch das Zeremoniell also die internen Hierarchien, Kompetenzen und Ansprüche am Hof fixiert, um Ehrenhändel und andere Konflikte in der Hofgesellschaft zu vermeiden. Zum anderen wurden die Fragen des Vortritts und der Etikette im ,interhöfischen' Verkehr normiert. Schließlich zielte das Zeremoniell auf die symbolische Darstellung der Macht des Fürsten vor einer breiteren Öffentlichkeit. Die genau festgelegten, auf den Herrscher ausgerichteten Verhaltens- und Bewegungsweisen der Höflinge und die allgemeine Prachtentfaltung des Hofes sollten den Herrscher als das aus der Sphäre des Alltags herausgehobene Kraftzentrum seines Staates erscheinen lassen. Sie sollten ihn in die Nähe des allmächtigen Gottes rücken, dessen Stellvertreter auf Erden er war.“"

Die dritte von Andreas Gestrich genannte Funktion - Darstellung der herrschaftlichen Macht vor einer breiten Öffentlichkeit, die das eigene Volk einschloss - war offenkundig von zentraler Bedeutung. Denn auch im Urteil zeitgenössischer Autoren waren die Untertanen Adressaten derartiger Zeremonielle, wie Christian Freiherr von Wolff 1736 konstatierte: Der gemeine Mann, welcher bloß an den Sinnen hanget, und die Vernunfft wenig gebrauchen kan, vermag auch nicht zu

1 Juliane Riepe, Hofmusik in der Zeremonialwissenschaft des 18. Jahrhunderts, in: Händel-Jahrbuch 49 (2003), S. 27-52, hier S. 29.

2 Andreas Gestrich, Höfisches Zeremoniell und sinnliches Volk. Die Rechtfertigung des Hofzeremoniells im 17. und 18. Jahrhundert, in: Jörg Jochen Berns/Thomas Rahn (Hg.), Zeremoniell als höfische Ästhetik in Spätmittelalter und Früher Neuzeit, Tübingen 1995, S. 57-73, hier S. 57 f. 
begreiffen, was die Majestät des Königes ist: aber durch die Dinge, so in die Augen fallen und seine übrigen Sinne rübren, bekommet er einen obzwar undeutlichen, doch klaren Begriff von seiner Majestät, oder Macht und Gewalt. ${ }^{3}$

Innerhalb des höfischen Zeremoniells hatten musikalische Darbietungen einen hohen Stellenwert. Wie dieses System im Detail strukturiert war, welche Aufgaben die Musik darin übernehmen konnte, welche Formationen für die Ausführung jeweils herangezogen wurden und welchen ästhetischen und/oder zeremoniellen Anforderungen sie zu genügen hatten, ist bislang nur ansatzweise erforscht. Sabine Henze-Döhring hat angemahnt, Musik nicht nur einseitig als nicht-diskursives, gleichwohl prozesshaftes „Element des höfischen Zeremoniells zu sortieren" und dabei Oper und Ballett als die bedeutsamsten repräsentativen musikalischen Kategorien auf ihre Funktionalität hin näher zu untersuchen, sondern die Komplexität der „synästhetischen Verknüpfung“ aller Bereiche der Hofkunst zu erfassen: „Architektur, Musik, Poesie und Choreographie vereinigen sich wesentlich unter dem Zeichen der sinnlich-affektiven Vergegenwärtigung höfischer Hierarchien oder einer programmatischen Aussage im Kontext der repraesentatio majestatis." 4

Diese „sinnlich-affektive Vergegenwärtigung“ der höfischen Hierarchien manifestierte sich freilich nicht allein in der Verbindung von Musik und optischen Eindrücken auf der rein künstlerischen Ebene - etwa der Repräsentation auf der Opernbühne, in der neben der darstellerisch-künstlerischen Leistung von Solisten, Chor, dem Corps de Ballett oder der Kapelle das Bühnenbild und die Kostüme der Darsteller natürlich ebenfalls bedeutsam waren ${ }^{5}$-, sondern auch in der Verbindung mit anderen visuellen Elementen, die keine eigentliche künstlerische Qualität besitzen: etwa von Musikdarbietung und Uniform bzw. Exerzieren in der Militärmusik; von Musikdarbietung und anderen herrschaftlichen Verrichtungen, beispielsweise bei der Jagd, bei solennen Ein- und Ausfahrten inklusive der winterlichen Schlittenfahrten. Oder schlicht bei Konzerten, in denen die Kapellmitglieder eine mehr oder weniger kostbare Livree trugen.

Für die musikalische Zelebrierung der majestas hat Sabine Henze-Döhring folgende Gruppierungen bzw. Gattungen benannt: ${ }^{6}$

3 Christian Freiherr von WolfF, Vernünfftige Gedancken von dem gesellschafftlichen Leben der Menschen und insonderheit dem gemeinen Wesen [...], Frankfurt/

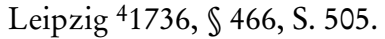

4 Vgl. Sabine Henze-DöHring, Der Stellenwert der Musik im höfischen Zeremoniell, in: Juliane Riepe (Hg.), Musik der Macht - Macht der Musik. Die Musik an den sächsisch-albertinischen Herzogshöfen Weißenfels, Zeitz und Merseburg (Schriften zur Mitteldeutschen Musikgeschichte 8), Hamburg 2003, S. 23-32, hier S. 24. Gleichwohl bezeichnete die Autorin die Oper als „,Majestät' unter den musikalischen Gattungen“; ebd., S. 31.

5 WolfF, Vernünfftige Gedancken (wie Anm. 3), \$390, S. 382 hebt explizit die Bedeutung der Theater-Maschinerie für die Steigerung der Wirkung hervor: Comödien, Tragödien und Opern können gleichfalls das ibrige dazu beytragen, absonderlich wenn durch theatralische Machinen allerhand vorgestellet wird, so uns in Verwunderung setzet.

6 Henze-Döhring, Musik im höfischen Zeremoniell (wie Anm. 4), S. 26. 
Für einen großen und bedeutenden Hof [am Beispiel Dresdens]:

die Hofkapelle incl. der Kammermusik-Formationen

die italienische Oper

das französische Ballett

die Hoftrompeter und -pauker.

Für einen kleinen bis mittelgroßen Hof [„Mindestausstattung“]:

die Hofkapelle [„kammermusikalische Ausrichtung“]

Hoftrompeter und -pauker.

Es bleibt kritisch anzumerken, dass die Verfasserin die Hautboisten-Bande gänzlich außer Betracht gelassen hat. Diese leistete an vielen Höfen einen ganz entscheidenden Beitrag zur Entwicklung der Leistungsfähigkeit der jeweiligen Hofkapelle, mithin auch zu deren ,Nutzbarkeit im Rahmen der repraesentatio majestatis, ${ }^{7}$ und übernahm zudem als eigenständige Formation wichtige Aufgaben bei zeremoniellen Veranstaltungen. ${ }^{8}$ Zudem war die Schichtung der Musikformationen mancherorts sehr viel weniger rigide, als von Henze-Döhring angenommen. Allgemein fand im Laufe des 18. Jahrhunderts eine beständig zunehmende Vermischung der Angehörigen der verschiedenen Musikergruppen statt, auch und gerade zum Zweck der Repräsentation. Und nicht zuletzt legen einschlägige Quellen den Schluss nahe, dass es für die Darstellung nach außen wie nach innen nicht allein auf die nominelle Größe der Kapelle und auf deren musikalische Qualität ankam, sondern auch auf die Verwendung der jeweils neuesten, ,modernsten“ Instrumente ${ }^{9}$ oder die Nutzung neu entwickelter Spieltechniken (wobei auch hier das optische Element eine nicht zu vernachlässigende Bedeutung hatte). Die visuelle Wirkung von Musikinstrumenten wird heute zumeist unterschätzt bzw. ihrer musikalisch-klanglichen untergeordnet, was den historischen Gegebenheiten nicht entspricht. So zeigen beispielsweise Rechnungen über die Anfertigung von Paukenschlegeln im 18. Jahrhundert, dass man auf das Äußere dieses Accessoires großen Wert legte, obschon es musikalisch keinerlei Auswirkungen hatte. Dafür ein konkretes Beispiel. Einer Rechnung des Weimarer Hofdrechslers vom 8. März 1731 zufolge fertigte er im Auftrag des Herzogs Ernst August I.: 1 Paar Paukenschlegel mit Elffenbein für 16 Gr[oschen; 24 Groschen = 1 Taler]; 5 Paar Pauken-

7 Christian Ahrens, „Zu Gotha ist eine gute Kapelle ...“. Aus dem Innenleben einer thüringischen Hofkapelle des 18. Jahrhunderts (Friedenstein-Forschungen 4), Stuttgart 2009, Kap. 7, hier insbesondere S. $291 \mathrm{f}$.

8 Siehe unten.

9 Vgl. etwa die Angaben von Riepe, Hofmusik in der Zeremonialwissenschaft (wie Anm. 1), S. 41 zur Wirkung, die Pantaleon Hebenstreit durch sein Spiel auf dem nach ihm benannten Pantalon (einem verbesserten Hackbrett) erzielte, als Erzherzog Karl, der spätere Kaiser Karl VI., Anfang Oktober 1703 mit großem Gefolge die Residenz des Herzogs Johann Georg von Sachsen-Weißenfels besuchte. 
schlegel mit schwarzen Horn für 1 Thlr. 11 Gr.; 1 Paar kleine Paukenschlegel von Eben Holz mit Elffenbein für $8 \mathrm{Gr}^{10}$

Im Vergleich zu jenen Repräsentationsformen, die im Zentrum der modernen Forschung stehen, fasste Julius Bernhard von Rohr ${ }^{11}$ den Kreis wesentlich weiter. Im Teil vier seiner Einleitung zur Ceremoniel-Wissenschafft beschrieb er unter dem Titel „Hoch-Fürstliches Divertissement“ folgende Veranstaltungsarten: Aufzüge, Turniere, Caroussells, Ringrennen, Rossballette, Konzerte, Tänze, Bälle, Opern, Komödien, Maskeraden, Wirtschaften, Bauernhochzeiten, ${ }^{12}$ Schlittenfahrten, Illuminationen, Feuerwerke, Lustschießen, Jagden. Hinzu kamen darüber hinaus diverse Feierlichkeiten aus familiären Anlässen - von Geburten über Kindtaufen, Geburtstage, Hochzeiten bis zu Sterbefällen - sowie staatspolitische Akte, wie Fürstenzusammenkünfte, Land- oder Ständetage etc. ${ }^{13}$ Dass sich darüber hinaus zahlreiche weitere Gelegenheiten boten, auf der Basis genauer zeremonieller Regelungen bestimmte musikalische Aktivitäten gleichsam zur Schau zu stellen, wird im Folgenden zu zeigen sein.

Die Fokussierung musikwissenschaftlicher Forschungen auf Oper und Ballett - wofür nicht zuletzt eine entsprechend große und leistungsfähige Hofkapelle erforderlich war - sowie auf die zweifelsohne besonders repräsentative Formation von Trompetern und Paukern greift ebenso zu kurz wie die Beschränkung auf den Hof im engeren Sinne, d. h. das jeweilige Schauspiel- bzw. Opernhaus und die Gemächer im Schloss. Immerhin gab es Höfe, die sich den Luxus einer feststehenden Oper nicht leisten konnten oder wollten, gleichwohl jedoch den Anspruch erhoben, eine besondere Stellung unter den regionalen ,Konkurrenten' einzunehmen. Trompeter und Pauker hielt sich wohl jeder Fürst. Aber nur auf den ersten Blick liefert deren Anzahl ein direktes Abbild des jeweiligen Ranges innerhalb vergleichbarer Herrschafts-Strukturen. Denn, auch wenn ein Hof nur wenige dieser Musiker mit ihrer immensen zeremoniellen Außenwirkung hielt, konnte, wie noch dargelegt werden soll, durch Einbeziehung anderer Musiker, welche das

10 Thüringisches Hauptstaatsarchiv Weimar (im Folgenden: HStA Weimar), Fürstenhaus A 870, Schatullrechnungen 1. November 1729 bis 1. Januar 1733, Beleg Nr. 39b, fol. 57r. Anfang 1731 hatte der Drechsler als Material für Schlegel u. a. Kokosnuss [sic!], Knochen und Horn verwendet.

11 Julius von RoHr, Einleitung zur Ceremoniel-Wissenschafft der grossen Herren [...], Berlin 1733, 4. Teil: Von denen Divertissements, Kap. I-XIV, S. 732-880. HenZeDöHring, Musik im höfischen Zeremoniell (wie Anm. 4), S. 26 führt Rohrs Zusammenstellung zwar an, geht im Verlauf ihres Beitrages aber nicht dezidiert darauf ein.

12 Mit „Wirtschaften“ und „Bauernhochzeiten“ sind höfische Festlichkeiten gemeint, bei denen die Adligen sich als Bauern oder andere einfache Leute verkleideten und sich in einer imaginären ,natürlichen' Landschaft bewegten.

13 Vgl. hierzu Oтto Mörtzsch, Die Dresdner Hoftrompeter, in: Mitteilungen des Vereins für Geschichte Dresdens 29 (1921), S. 64, der für die Hoftrompeter im Königreich Sachsen eine weitgehend identische Zusammenstellung ihrer zeremoniellen Aufgaben liefert; diese hatten sie bis zum Ende der Monarchie 1918 zu erfüllen. 
eigentliche Trompeter-Corps verstärkten, die Wirkung dieser Formation beträchtlich gesteigert werden.

Juliane Riepe ${ }^{14}$ hat das Beispiel des Herzogs von Braunschweig-Calenberg angeführt, der die Kurfürsten-Würde zu erlangen suchte und sich dafür in Hannover eine Operntruppe hielt, diese jedoch nach Erlangung der Kurwürde wieder auflöste. Hier wird deutlich, dass sich die Oper als reines Machtinstrument einsetzen ließ, weitgehend entkoppelt von spezifisch künstlerischen Vorstellungen. Denn natürlich hatte der neu ernannte Kurfürst nicht nur weiterhin seine herrschaftliche Bedeutung zur Schau zu stellen, sondern in seiner gesteigerten Würde sogar ein Mehr an zeremonieller Außendarstellung aufzubringen. Wenn er glaubte, dafür die Oper nicht mehr zu benötigen, dann musste er diesen ,Mangel` durch die Steigerung der Repräsentationswirkung auf anderer Ebene kompensieren. Die repräsentativen Mittel waren also, wie Riepe zu Recht konstatiert, in gewisser Weise substituierbar: „Die Zeichensysteme der Repräsentation scheinen untereinander mindestens ein Stück weit austauschbar zu sein: ein Fürst, dem sein Etat nicht erlaubt, sich aller Medien der höfischen Repräsentation zu bedienen, wählt unter ihnen aus; er kultiviert vielleicht Parforce-Jagd und Baukunst, aber nicht Musik und kümmert sich weder um Gartenarchitektur noch um eine Gemäldesammlung. Diese Konzentration auf ein Zeichensystem gibt ihm vielleicht sogar die Möglichkeit, auf diesem einen Spezialgebiet ein Prestige zu erringen, das er mit einer Hofkulturpflege nach dem Gießkannenprinzip (überall ein wenig) nie hätte erreichen können. Konkret: indem sich der Weißenfelser Herzog Johann Adolf auf die deutschsprachige Oper kapriziert, umgeht er nicht nur die Konkurrenz mit der Dresdner Verwandtschaft, die er ohnehin nicht bestehen könnte, sondern leistet sich auch etwas Eigenes, in dieser Einzigartigkeit überaus Prestigeträchtiges." 15

Die eingesehenen Quellen belegen in der Tat, dass es dem Souverän freistand, nicht nur die Art der Medien für die höfische Repräsentation gezielt auszuwählen, sondern auch die Größe der jeweiligen Formationen entsprechend bestimmten zeremoniellen - d. h. im Wesentlichen: staatspolitischen - Erfordernissen variabel zu gestalten. So ist überliefert, dass am kursächsischen Hof zu Dresden im Laufe des 17. Jahrhunderts in der Regel 12 Trompeter und 1 bis 2 Pauker angestellt waren. ${ }^{16}$ Aber bereits Otto Mörtzsch hatte darauf hingewiesen, dass die Zahl in den Jahren 1629 und 1680 aufgestockt wurde: 1629 auf 14 Trompeter, 1680 sogar

14 Riepe, Hofmusik in der Zeremonialwissenschaft (wie Anm. 1), S. 36.

15 Ebd., S. 37 f. (Hervorhebungen original). Vgl. hierzu auch die Ausführungen bei WolfF, Vernünfftige Gedancken (wie Anm. 3), $\$ 487$, S. 578. Zwar thematisiert er ausschließlich die optische Vermittlung von Pracht und Macht, aber seine Vorstellungen sind zweifellos auf alle Arten von Musikproduktionen zu übertragen: Man muß Lust=Häuser und Lust=Schlösser anlegen, wo man verschiedenes zu seben bekommet, was man sonst an anderen Orten nicht findet.

16 Vgl. Mörtzsch, Dresdner Hoftrompeter (wie Anm. 13), S. 47. Die Vergrößerung könnte auch im Hinblick auf den 1630 in Regensburg zusammengetretenen Kurfürstentag erfolgt sein. 
auf 19. Zwar nannte Mörtzsch für diese zusätzlichen Einstellungen keine Gründe, aber es liegt angesichts der noch zu schildernden Vorgänge von 1692/93 nahe anzunehmen, dass die Vergrößerung der Zahl der Trompeter und damit die Verstärkung des Repräsentations-Potenzials mit den Ereignissen während des Dreißigjährigen Krieges bzw. mit dem Tod des Kurfürsten Johann Georg II. (1613-1680) in Zusammenhang stehen. ${ }^{17}$ Dass sächsische Kurfürsten staatspolitisch bedeutsame Ereignisse zum Anlass nahmen, kurzfristig ihr Trompetercorps zu verstärken, ist für 1692 eindeutig belegt. Zur Vorbereitung der Hochzeit von Friedrich August I. (1670-1733; reg. 1694-1733), Bruder des regierenden Kurfürsten Johann Georg IV. (1668-1694), am 20. Januar 1693, ersuchte ein Hofbeamter im Namen des Herrschers mit Schreiben vom 31. Oktober 1692 den GeneralWachtmeister Freiherr von Bronn[e] um die Abgabe eines Militärtrompeters an den Hof. Der Kurfürst beabsichtige, die Zahl seiner Trompeter von derzeit 20 auf nunmehr $24 \mathrm{zu}$ erhöhen und wolle zum Hochzeitstermin die zabl gerne voll haben. ${ }^{18}$ Die Angaben in der einschlägigen Literatur ${ }^{19}$ zur Anzahl der Hofbediensteten, namentlich der Trompeter und Pauker, sind daher mit großer Vorsicht $\mathrm{zu}$ interpretieren, denn sie spiegeln weder die bei Bedarf ad hoc vorgenommene Vergrößerung des Corps wider, ${ }^{20}$ noch dessen häufig zu beobachtende (und im Weiteren zu diskutierende) Verstärkung durch Abordnung oder Beiziehung von Musikern aus dem Militär oder anderen Musik-Formationen.

Was mir jedoch wichtiger erscheint und was ich im Folgenden an Beispielen erläutern möchte: Die Systeme ließen sich, sozusagen in einer Art Baukastenprinzip, weitgehend beliebig miteinander kombinieren und so in ihrer Wirkung potenzieren. Augenscheinlich fand dieses Verfahren unabhängig von der Größe und finanziellen Leistungsfähigkeit des betreffenden Hofes Anwendung, denn es existieren Belege dafür sowohl an kleineren mitteldeutschen Höfen als auch am kursächsischen Hof zu Dresden.

In ihrer Arbeit über das Tafelzeremoniell legte Claudia Curtius Seutter von Lötzen dar, dass bei der Mehrzahl der zeremoniellen Anlässe an einem Hof „die Untertanen - zumindest unmittelbar - ausgeschlossen“ waren und knüpfte daran

17 Vgl. Carl Wilhelm Böttiger, Geschichte des Kurstaates und Königreiches Sachsen, Bd. 2, Hamburg 1831, S. 181-185.

18 Sächsisches Staatsarchiv - Hauptstaatsarchiv Dresden (im Folgenden: HStA Dresden), Oberhofmarschallamt, K III Nr. 6; Notificationes an das Cammer=Collegium Hof=Diener in Livrée betr. von Anno 1662 bis mit 1701. Churfürstl. Hoff-Trompeter und Heer Paucker, fol. 46r/v, hier fol. 46v.

19 Vgl. etwa die von Detlef Altenburg, Untersuchungen zur Geschichte der Trompete im Zeitalter der Clarinblaskunst (Kölner Beiträge zur Musikforschung 75), Regensburg 1973, Bd. 1, S. 11-30, für Dresden S. 11 f., vorgelegten Statistiken.

20 Die zusätzlichen Trompeter wurden, wie im oben geschilderten Fall, zumeist aus den Militärformationen übernommen (vgl. dazu auch MörTzsch, Dresdner Hoftrompeter (wie Anm. 13), S. 47) und konnten, falls ihre Verwendung nicht mehr erforderlich war, dorthin wieder abgegeben werden. Andernfalls ließ man einfach die nächste vacante Trompeter-Stelle unbesetzt. 
die Frage, wie sie dann Adressaten des entsprechenden Aufwandes und des Zeremoniells gewesen sein könnten. Zugelassen zum höfischen Leben waren die Untertanen nach Ansicht der Autorin bis ins 18. Jahrhundert hinein lediglich zu öffentlichen Fußwaschungen des Kaisers, zu Prozessionen, Aufzügen, sowie Trauer- und Herrschereinzügen und zur öffentlichen Tafel. ${ }^{21}$

Auch hier bleiben einige weitere bedeutsame Anlässe bzw. Aktivitäten unerwähnt. Einerseits die, welche sich innerhalb der Kirche abspielten, andererseits jene, die bei den herrschaftlichen Vergnügungen im Zusammenhang mit MilitärParaden etc. sowie Jagden stattfanden.22 Und schließlich all die Arten, die von Rohr in seinem Buch ebenfalls aufgezählt hat. Bedeutsam erscheint allerdings Seutter von Lötzens Schlussfolgerung, dass das Volk nicht allein ,Adressat ${ }^{\prime}$ der jeweiligen zeremoniellen Inszenierungen war, sondern zugleich deren ,Bestandteil', dass es gewissermaßen als Staffage diente, wobei es im Sinne der Inszenierung darauf ankam, einen möglichst großen Anteil des Volkes im Umfeld der Zelebrierung einzubeziehen. Dass dafür weder die relativ kleinen und zumeist innerhalb des jeweiligen Schlosskomplexes gelegenen Opernsäle geeignet waren, noch überhaupt Aktivitäten in den Räumlichkeiten der Herrscherresidenz, die gegenüber Außenstehenden weitgehend abgeschottet war, ist evident. Wesentlich besser vermochten hingegen Veranstaltungen innerhalb der Kirche sowie militärische Zeremonien im Freien diesen Zweck zu erfüllen: In und bei ihnen konnte das Volk sowohl als Akteur wie auch als Adressat der Schaustellung fungieren. Und zwar als Akteur im Sinne von Statisten, wie Barbara Stollberg-Rilinger herausstellte: „Plausibler scheint mir vielmehr, daß die Untertanen als Statisten eine wesentliche Rolle zu spielen hatten: Eine prächtige Solennität bedurfte zu ihrem Gelingen einer gewaltigen Masse an jubelndem und akklamierendem Volk. Eindruck sollte damit vor allem auf die sozial und politisch relevanten Beteiligten und Beobachter gemacht werden: Auswärtige Gäste und Gesandte sollten an ihren Höfen davon berichten, und die regelmäßig veröffentlichten und an andere Höfe verschickten Fest-Diarien ${ }^{23}$ sollten davon Zeugnis ablegen."24

Im Folgenden soll anhand zeitgenössischer Quellen ${ }^{25}$ aus Gotha, Weimar und Dresden näher untersucht werden, in welchem Umfang die visuelle Wahrneh-

21 Claudia Curtius Seutter von Lötzen, Das Tafelzeremoniell an deutschen Höfen im 17. und 18. Jahrhundert - Quellen und Rechtsgrundlagen, Diss. Jena 2008, S. 34 f.; Internetversion:http://deposit.ddb.de/cgi-bin/dokserv?idn=990726347\&dok_var=d1\& dok_ext=pdf\&filename=990726347.pdf (Zugriff am 20. August 2012). Vgl. dazu weiter unten die Ausführungen zum sogenannten Campement von 1730.

23 Ausführliche Berichte in Zeitungen, aus denen nachfolgend noch zitiert werden wird, erfüllten natürlich eine ähnliche Funktion.

24 Barbara Stollberg-Rilinger, Hofzeremoniell als Zeichensystem. Zum Stand der Forschung, in: Riepe, Musik der Macht (wie Anm. 4), S. 11-22, hier S. 17.

25 Ich danke der Fritz Thyssen Stiftung Köln, die durch ein Stipendium die zeitaufwendigen Archivarbeiten in Gotha, Weimar und Dresden ermöglichte, und den dortigen Archiven (Thüringisches Staatsarchiv Gotha; Stadtarchiv Weimar; Thüringisches Hauptstaatsarchiv Weimar und Sächsisches Staatsarchiv - Hauptstaatsarchiv Dresden) dafür, dass sie mir Zugang zu den Quellen gewährten und deren Auswertung gestatteten. 
mung in die Zelebrierung herrschaftlicher Macht durch musikalische Mittel eingebunden war. Dabei möchte ich das Augenmerk auf die gezielte Nutzung musikalischer Gattungen und von Örtlichkeiten richten, die in der einschlägigen Diskussion bislang weitgehend unbeachtet blieben, sowie auf den Einsatz anderer Musiker als jener, die gemeinhin als zentral für die Machtdarstellung angesehen werden. Nicht zuletzt soll gezeigt werden, dass die künstlerische Qualität (im heutigen Verständnis des Wortes) zeremonieller Musik zumeist nur von untergeordneter Bedeutung war, und dass die Wirkung einzelner musikalischer Repräsentationsmittel durch gezielte Kombination mit anderen - musikalisch-klanglichen, vornehmlich jedoch optischen Elementen - gesteigert werden konnte. Grundlage dieser Massierung von Mitteln zur Darstellung herrschaftlicher Macht scheint mir die bewusste Suche nach dem Besonderen zu sein, das Bestreben, sich deutlich von den zeremoniellen Leistungen und Standards anderer Höfe abzugrenzen. Und zwar aus dem Bestreben heraus, die mittels des Zeremoniells anzusprechenden Individuen in möglichst große Verwunderung ${ }^{26}$ zu setzen.

Vorab sei jedoch ein Typus der Macht-Darstellung angesprochen, der sich gleichsam als reziproke repraesentatio majestatis interpretieren lässt: die Bezeugung von Ehrerbietung gegenüber einem Herrscher durch seine Untertanen mit eben den musikalischen Mitteln, die dieser selbst gewöhnlich zur Außendarstellung einsetzte. Es ist klar, dass für eine solche Huldigung durch die Bevölkerung bzw. deren ständische Repräsentanten nur einige wenige Zeremonialien zur Verfügung standen, beispielsweise der Einsatz der städtischen Musikformationen mit Pauken und Trompeten, der Klang von Kirchenglocken und Böllerschüssen sowie das Zelebrieren des Te Deums. ${ }^{27}$ Ein Bericht der Weimarer Zeitung vom 23. Februar 1805 aus Bürgel, ca. $35 \mathrm{~km}$ östlich von Weimar gelegen, beschreibt Art und Charakter jener zeremoniellen Klangereignisse, die dazu dienen sollten, die Erhabenheit des Herrschers - hier der Zarentochter Maria Pawlowna (1786-1859), Gemahlin des Erbprinzen und nachmaligen Großherzogs Carl Friedrich (17831853; reg. 1828-1853) - zu preisen sowie Ehrfurcht und Respekt der Untertanen auszudrücken, besonders prägnant: Feierlichkeit zu Bürgel. Das hohe Geburtsfest unserer allergnädigsten Fran Erbprinzessin, Maria, Kaiserl. Hoheit wurde am 17. d. M. von der Bürgerschaft und dem Rath der Stadt Bürgel durch Veranstaltung des dasigen Bürgermeisters, Hofadvocat Schwabe, feierlich begangen. Um 8 Uhr erklangen unter dem Donner der Kanonen alle Glocken, und in getheilten Chören ertönten auf dem Markt und von der Ehrenpforte Trompeten und Pauken, wobey nach der zweiten Pause der Musik sich die Innungen mit fliegenden Fabnen versammelten und einen balben Zirkel auf dem Markte bildeten. Bis 9 Ubr ertön-

26 Wolff, Vernünfftige Gedancken (wie Anm. 3), \390, S. 382.

27 Rohr, Ceremoniel-Wissenschafft (wie Anm. 11), Teil 3, Kap. X: Von der Ehre und Devotion, so die Unterthanen gegen ihre Landes=Herrschafft abstatten, S. 724-731, widmet den Huldigungen des Herrschers durch seine Untertanen ein ganzes Kapitel und beschreibt (insbesondere S. 730) auch die dabei gebräuchlichen musikalischen Mittel. 
ten abwechselnd Trompeten und Pauken in dem Donner der Kanonen, und dann zogen Amt, Rath und Bürgerschaft in feyerlicher Prozession unter Läutung aller Glocken in die Kirche, [...]. Es weckte dieselbe [eine Kantate] die reinsten Gefüble der Hörer [...]. Hierauf wurde von dem Hrn. Superintendent Bertram eine vortreffliche, auf des Tages Feyerlichkeit passende Predigt gebalten, und nach derselben ein feierliches: Herr Gott, dich loben wir! unter Abfeuerung der Kanonen abgesungen. Der Zug ging nun unter Musik wieder zurück. Tausende strömten berbey, Tausende froblockten laut auf; ein herzlicher Frobsinn belebte alle. - Auf dem Ratbhause war Tafel, zu welcher die anwesenden fremden Honoratioren eingeladen waren. Die Gesundheit der Frau Erbprinzessin und des hoben Fürstenhauses wurden unter Trompeten und Paukenschall und unter dem Donner der Kanonen getrunken [...]. ${ }^{28}$

Vom Prinzip her ähnlich, wenn auch im Detail anders gelagert waren die Verhältnisse bei einer Jubelfeier, die am 1. Dezember 1805 in Weimar stattfand und über die das Weimarische Wochenblatt drei Tage später ausführlich berichtete. Anlass der Zeremonien war die Aufstellung eines von Maria Pawlowna gestifteten, vom Maler Johann Friedrich August Tischbein (1750-1812) aus Leipzig gefertigten lebensgroßen Porträts der Prinzessin im Rathaus. In dem Zeitungsbericht heißt es: [...] Der erste Decemb., als der letztvergangene Sonntag war nun zu der Feyerlichkeit bestimmt. Zu dem Ende versammelten sich sämtliche Rathsglieder nebst den Viertelsmeistern hiesiger Stadt, gegen $11 \mathrm{Ubr}$ vormittags auf dem Rathbaus und um $11 \mathrm{Ubr}$, nach geendigten Gottes=Dienste, gingen sie paarweis, aus der Rathsstube auf den Rathssaal, woselbst das erhabene Bildniß auf einer großen Staffelei einstweilen aufgestellt worden war und wo sich die Obermeister und Beysitzer der hiesigen Innungen, welche dazu besonders eingeladen worden waren, nebst noch andern biesigen Bürgern und Einwobnern der Stadt zablreich eingefunden hatten. Nachdem der hies. Hof, und Stadt=Musikus Eberwein, mit einem gut besetzten Orchester ein Musikstück aufgefübrt hatte, trat der Herr Rath= und Bürgermstr. Schulze vor und bielt eine, der feyerlichen Handlung und der Würde des Gegenstandes sebr angemessene und würdige Rede. Hierauf wurde das Bildniß von dem Vergolder Herrn Golla, welcher den Ramen [sic!] dazu verfertiget hatte, und seinen Leuten von der Staffelei abgenommen und in die Ratbstube getragen, um es daselbst wirklich aufzustellen. Ibnen folgten die Rathsglieder und Viertelsmeister wieder paarweis, nebst den übrigen versammelten Personen. Sobald die Aufstellung geschehen war, hielt der Herr Rath= und Bürgermeister Schulze wieder eine kurze aber sebr zweckmäßige Rede, und endigte mit dem innigsten Wunsche für das lange und glückliche Leben der allgeliebten Fürstin, worauf mit innigster, sichtbarster Theilnabme von der ganzen Versammlung ein freudiges Lebeboch! unter Trompeten $=$ und Pauken=Schall gerufen wurde. Nachber beschloß der Stadtrath, diesen schönen, ibm und seinen Nachfolgern sebr denkwürdigen Tag alljäbrlich festlich zu erneuern. Uebrigens blieb diesen ganzen Tag über die Raths-

28 Weimarisches Wochenblatt, Nr. 16, 23. Februar 1805, S. 65 f., hier S. 65. 
stube geöfnet und jedermann wurde der Zutritt gestattet, von dem Stadtrathe aber, auf dem Stadthause, bey einem gemeinschaftlichen Mittagessen, die Gesundheit der verehrten Fran Erbprinzessin, so wie ibres thenersten Herrn Gemabls und des geliebten neu gebobrnen Prinzen Paul, ingleichen des ganzen Herzoglichen Hauses, unter Trompeten $=$ und Pauken=Schall ausgebracht..$^{29}$

In mehrfacher Hinsicht vermengen sich hier die Funktionen der Erbprinzessin und der Untertanen, der Schenkenden und der Beschenkten, der Agierenden und der Reagierenden und zugleich die Intentionen und Ansprüche beider Parteien. Die Bürgerschaft bedankt sich mit den geschilderten Aktivitäten für das ,huldreichst ${ }^{`}$ dargebotene Porträt der Prinzessin in Lebensgröße. Zugleich feiert man das freudige Ereignis, dessentwegen die Übergabezeremonie verschoben werden musste: die Geburt des Prinzen Paul Alexander Carl Constantin Friedrich August am 25. September 1805 (der Prinz verstarb bereits am 10. April 1806). Und nicht zuletzt feiern sich Bürgerschaft und Stadtrat selbst: gewissermaßen als gnädig Beschenkte. Letztlich demonstriert freilich die Erbprinzessin, die ja durch ihre Stiftung die zeremoniellen Aktivitäten erst ausgelöst hat, auf diese Weise indirekt ihren Herrschaftsanspruch.

Weder die beschriebenen Zeremonien, für die Bürgermeister und Stadtrat namens der gesamten Weimarer Bürgerschaft verantwortlich zeichneten, noch die dabei zur Repräsentation genutzten musikalischen und materiellen Mittel unterschieden sich nennenswert von jenen, die die Herrscher selbst zur Demonstration ihrer Macht und zur Ermunterung und Erbauung ihrer Untertanen einzusetzen pflegten. ${ }^{30}$ Alle Beteiligten bedienten sich der allseits bekannten musikalischen und sonstigen notwendigen Insignien. Zwar wurde nicht das Te Deum mit Trompeten und Pauken ausgeführt, aber das Volk incl. seiner Repräsentanten rief ein freudiges Lebehoch! unter Trompeten= und Panken=Schall - diese Form der Huldigung steht der Intonation des Te Deums, zumindest von der Funktion her, sehr nahe. Selbst ein Gastmahl, bei dem die Gesundheit der Stifterin und des ganzen herzoglichen Hauses unter Trompeten $=$ und Pauken=Schall ausgebracht wurde, richtete der Stadtrat aus. Indem er traditionelle musikalische Mittel der Machtdemonstration - Te Deum mit Pauken und Trompeten; Huldigungsmusik durch das Stadtmusikcorps; Tafelzeremoniell mit Gesundheit-Trinken sowie Paukenund Trompetenschall; dazu Kanonendonner und Glockengeläut ${ }^{31}$ - eines Herr-

29 Weimarisches Wochenblatt, Nr. 97, 4. Dezember 1805, S. 417 f., hier S. 418. Der Aufstellungstermin des Bildnisses wurde mehrfach verschoben, u. a. weil der Rathaussaal baulich erst entsprechend hergerichtet werden mußte. Tischbein hatte bereits zuvor Porträts von Mitgliedern der Weimarer Herzogsfamilie gemalt.

30 Vgl. hierzu die Beschreibung des Friedensfestes nach dem Ende des Dreißigjährigen Krieges am 19. August 1650 in Weimar: Johann Christian Lüning, Theatrum Ceremoniale Politicum, Oder Historisch= und Politischer Schau=Platz aller Ceremonien. [...], Bd. 1, Leipzig 1719, S. 828-834; Internetversion: http://diglib.hab.de/drucke/ge2f-5-2b-1s/start.htm (Zugriff am 19. September 2012).

31 Selbst die Verwendung des Glockengeläuts war seinerzeit hierarchisch gestuft. In einer Verordnung des Herzogs Johann Wilhelm von Sachsen-Eisenach (1666-1729) für die 
schers nur wenig verändert übernahm und dabei nicht zuletzt Aktionen einband, die durch ihren optischen Eindruck die zeremonielle Wirkung unterstützten bzw. steigerten (die Innungen postieren sich mit ihren Fahnen im halben Zirkel auf dem Marktplatz; feierlicher Einzug von Amt, Rath und Bürgerschaft in die Kirche unter Läutung aller Glocken (23. Februar 1805); die Rathsglieder gehen in einer Reihe paarweise von der Ratsstube in den Rathaussaal (1. Dezember 1805)), schlüpfte er gleichsam in die Rolle eines Souveräns. Das zeigt die Ambivalenz des Hof-Zeremoniells zu dieser Zeit.

Ebenfalls von der Weimarer Bürgerschaft getragen war jene Huldigung, welche die Einwohner ihrem Herzog im Dezember 1793 bei dessen Rückkehr aus dem Krieg darbrachten. Carl August (1757-1828; reg. 1775-1828) war seit 1787 preuBischer Generalmajor und hatte 1792/93 am ersten Koalitionskrieg gegen das revolutionäre Frankreich teilgenommen. Nachricht, von der Zurückkunft unsers Theuersten Landesherrn. Es war schon Mitternacht vom Sonntage, als das sebnliche Verlangen aller Unterthanen hiesigen Landes in Erfüllung ging, und unser thenerster Landesfürst aus dem gefabrvollen Feldzuge an der Grenze Deutschlands gegen Frankreich im höchsten Woblseyn hier unvermuthet ankam. Solchergestalt war die getrene Bürgerschaft nicht im Stande, ibrem besten Fürsten ibre Frende alsbald zu bezengen. Aber sie erbielte dagegen die Erlaubnis, am Montag Abends doch etwas zu thun. Die Häuser der Hauptstraßen und des Markt-Platzes, nebst den beyden Ratbhäusern wurden erleuchtet, wobey man die Musik, Paucken und Trompeten, welche auf dem Markte am gewöbnlichen Orte des Rathbauses sich befanden, börete, und bis gegen $11 \mathrm{Ubr}$ andauerte. Darauf wurde noch mit dem Musik-Chor bis nach Mitternacht die Stadt durchzogen und Jedermann bezeigte, wie frob ihn die glückliche Ankunft unsers theuersten Herzogs gemacht habe. Niemand wird vergessen, der Vorsebung Gottes dafür zu danken, daß unser gnaidigster Fürst bey der großen Gefahr unverlezt und wobl erbalten worden ist. ${ }^{32}$

Auch hier nutzten die Untertanen musikalische Symbole, die bei entsprechenden Anlässen ein Herrscher einsetzte: Pauken und Trompeten.

Noch einen Schritt weiter im Hinblick auf die Kombination unterschiedlichster Repräsentationsmittel und -ebenen ging man in Weimar bei den Feierlichkeiten zum 18. Geburtstag von Erbprinz Carl August 1775 und der damit verbundenen Volljährigkeitserklärung durch den Kaiser. In den Weimarischen Wöchentlichen

Durchführung von Verlöbnissen, Hochzeiten, Kindtaufen und Begräbnissen aus dem Jahre 1715 wird ( $(16)$ zwischen dem kleinen Geläute (für Hochzeiten von gemeinen Leuten) und dem großen Geläute (bei Hochzeiten von Adligen, geistlichen und weltlichen Amtspersonen etc.) unterschieden; vgl. Des Durchlauchtigsten Fürstens und Herrns, Herrn Johann Wilhelm, [...] Erneuerte Verordnung wie es hinführo in der Jenaischen Landes=Portion beÿ Verlöbnüssen, Hochzeiten, Kind=Taufften, Begräbnüssen, und anderen Zusammenkünfften gehalten, [...], Jena [1715]; Internetversion: http://digitale.bibliothek.uni-halle.de/vd18/content/titleinfo/1407527 (Zugriff am 25. August 2012).

32 Weimarische Wöchentliche Anzeigen, Nr. 101, 18. Dezember 1793, S. 405. 
Anzeigen konnte man dazu folgendes lesen: Schon bey Anbruch des letzt vergangenen Sonntags, als des 3ten Septembris, wurde die Stadt durch ein Chor Trompeten und Pauken des hies. Stadt-Musici zu einer froben Feyer des vor uns auf immer merkwürdigen Tages, der unsers Durchlauchtigsten Fürsten und Herrn, Herrn Carl August, Herzogs zu Sachsen=Weimar und Eisenach, Neunzehender [recte: Achtzehnter] Geburtstag war, und Höchst Ibroselben nach dem dazu eingegangenen kayserl. allergnädigsten Diplom die Volljäbrigkeit gab, ermuntert, um Gott, dem böchsten Regenten, der bisher in Ansebung unsers Durchlauchtigsten Fürstenhauses alles so wohl mit uns gemacht hat, in feyerlichsten Dank in seinen Vorböfen zu bringen. ${ }^{33}$

Die Stadt huldigt also ihrem neuen Souverän und stattet zugleich Gott Dank dafür ab, dass er bisher in Ansebung unsers Durchlauchtigsten Fürstenhauses alles so wobl mit uns gemacht hat. Zum Lob des Herrschers wie zum Lob Gottes beide Zielsetzungen lassen sich kaum differenzieren - spielen die Stadtmusiker mit Trompeten und Pauken auf. Nach der anschließenden Gratulationscour im Schloss, zu der sich die Herren Minister, Räthe und Cavaliers einfanden, um dem nun Selbstregierenden gnädigsten Fürsten den Handschlag zu leisten, trat zunächst die Kaufmannschaft in Aktion: Mit gnädigste[r] Erlaubniß überreichte sie ein auf diese große Begebenheit gerichtete[s] Glückwünschungs Carmen [...] und bezeigte so ibre tiefste Ehrfurcht. Dann wurde zeremonielle Tafel gehalten und dabei mit Trompeten und Pauken musiciret. Nach aufgehobener Tafel führte die Hofkapelle eine Kantate - auf einen Text des Hofrats Wieland - aus, und der abendliche Ball rundete schließlich die Festivität ab. Nach gänzlich geendigter dieser feyerlichen Handlung hatte die hiesige Kaufmannschaft die gnädigste Erlaubniß, mit Ueberreichung eines auf diese große Begebenheit gerichteten Glückwünschungs Carmens in die Hände des Herrn Herzogs ibre tiefste Ehrfurcht zu bezeigen. Im Saal und Nebenzimmer wurde darauf an verschiedenen Tafeln gespeiset, und wäbrend dieser Zeit mit Trompeten und Pauken musiciret. Nach aufgebobener Tafel und eingenommenen Coffee hatte die Fürstliche Capelle die Ebre eine feyerliche Cantate aufzufübren, worzu der Herr Hofrath Wieland den Text gegeben und der Herr Capellmeister Wolf die Musik gesetzt hatte. Abends war Ball, zu dem die Ganze Noblesse eingeladen war, und nach eingenommenen Soupee wurde dieser frobe Tag geendiget. ${ }^{34}$

33 Weimarische Wöchentliche Anzeigen, Nr. 71, 6. September 1775, S. 289 f., hier S. 289.

34 Zur Bedeutung von Bällen im höfischen Zeremoniell vgl. RoHr, CeremonielWissenschafft (wie Anm. 11), 4. Teil, Kapitel V: Von den musicalischen Concerten / Tantzen / Bällen und Ballettten, S. 784-796, hier S. 787 f.: Die Bälle sind ein allgemeines Divertissement, so gemeiniglich mit den übrigen Solennitäten oder Lustbarkeiten vergesellschafftet ist. Wenn die Hoch=Fürstl. Personen nebst den anwesenden fremden Herrschafften, oder ibre eigene Hofstatt an solennen Cour=Tägen, oder bey andern Festivitäten von der Tafel aufgestanden, so wird hernach getantzt. In dieser Funktion als krönender Abschluß einer Festivität wurden Bälle seit Ende des 18. Jahrhunderts in zunehmendem Maße auch bei bürgerlichen Feiern (vgl. zur Situation in Bad Lauchstädt, 
Die enge Verbindung von Huldigung - des Herrschers - und Lobpreisung Gottes (gleichsam ein ,Te Deum') - Danksagung für den Schutz, den Gott dem neuen Souverän und den Untertanen gleichermaßen hatte angedeihen lassen -, von Stadtund Hofmusikern, von Bürgern und Adligen, von Zuschauern, Aktivisten und Adressaten der Zeremonien, spiegelt bereits die Überschrift des Zeitungsberichts wider; sie lautet: Nachricht von der Feyerlichkeit bey Hofe und in der Stadt am 3ten September.

Unklar ist, ob und gegebenenfalls inwieweit die jeweiligen Hofverwaltungen bei derartigen Veranstaltungen konkrete Vorgaben hinsichtlich des Zeremoniells machten, welche die Bürger zu respektieren hatten. Julius von Rohr jedenfalls schrieb unmissverständlich: Die Bürger der Hoch=Fürstlichen Residenz bekommen nicht selten vom Hofe Befehl zu Bezengung ibrer Devotion, der Herrschafft mit entgegen zu ziehen, und den solennen Einzug vermehren zu helffen. Sie theilen sich alsdenn in besondere Compagnien mit unterschiedenen Fabnen, die von den Ratbsherren oder andern Häuptern aufgefübret werden. Sie putzen sich und ibre Pferde aus, so gut als ibnen möglich und fübren ebenfalls bißweilen ibre Trompeter und Heer $=$ Paucker mit sich. ${ }^{35}$

Hinsichtlich der zitierten Beispiele aus Weimar muss offen bleiben, ob die Herrschenden ihren Untertanen die Huldigungen zum Zwecke der eigenen Machtdemonstration auferlegten, oder ob das Volk sich aufgrund individueller bürgerlicher Initiative artikulierte. Dass bei der gemeinsamen Huldigung 1775 schon aus organisatorischen Gründen eine Absprache und weitgehende Abstimmung erforderlich war, darf man sicher unterstellen.

\section{Gattungen}

\section{Kirchenmusik - Das Te Deum}

Was jene musikalischen Gattungen betrifft, die als allseits be- und anerkannte Möglichkeiten der Außendarstellung häufig diskutiert wurden, so verwundert, dass man in der einschlägigen Literatur zum Zeremonialwesen nur selten die Kirchen- ${ }^{36}$ und die Militärmusik genauer in Betracht zog. Dabei belegen Quellen, die

dessen Theater von Weimar aus bespielt wurde, Friedrich Arnold, Chronik von Lauchstädt, Bad Lauchstädt 1881, S. 64) und insbesondere bei den Aktivitäten der Militärmusiker veranstaltet (vgl. dazu Christian Ahrens, „Concert Abendessen und Ball“. Neue Strategien und deren Auswirkungen in der Militärmusik nach 1800, in: Wissenschaftliches Jahrbuch der Tiroler Landesmuseen 2010, S. 13-27).

35 Rohr, Ceremoniel-Wissenschafft (wie Anm. 11), \$23, S. $621 \mathrm{f}$.

36 Es liegen nur wenige Arbeiten zu dieser Gattung vor; so etwa Friedrich Wilhelm RiEDEL, Kirchenmusik am Hofe Karls VI. (1711-1740). Untersuchungen zum Verhältnis von Zeremoniell und musikalischem Stil im Barockzeitalter, München/Salzburg 1977; Ders., Kirchenmusik als politische Repräsentation. Zur Vertonung des Te Deum laudamus im 18. und 19. Jahrhundert, in: Peter Ackermann/Ulrike Kienzle/Adolf Nowak (Hg.), Festschrift für Winfried Kirsch zum 65. Geburtstag, Tutzingen 1996, 
bis weit ins 19. Jahrhundert hineinreichen, dass gerade in der katholischen Kirchenmusik die zeremoniellen und repräsentativen Aspekte musikalischer Darbietungen eine zentrale Rolle spielten. Das manifestiert sich insbesondere in der Bedeutung, die Trompeten und Pauken zukam: weniger im Rahmen ,echter kirchenmusikalischer Aktivitäten, etwa der Mitwirkung bei der Aufführung von Messen, Requiems oder anderer komponierter liturgischer Musik, sondern vielmehr in der zeremoniellen Eröffnung und im Abschluss des eigentlichen religiösen Zeremoniells.

Einer der Gründe dafür, dass die Kirchenmusik erstaunlich oft unbeachtet blieb, könnte darin liegen, dass sie, wie Juliane Riepe konstatierte, in der Zeremonialliteratur meist nicht explizit erwähnt wird. ${ }^{37}$ Erst in jüngster Zeit rückte die Funktion von Trompeten und Pauken - als herausragende und vergleichsweise eindeutige musikalische Herrschaftssymbole - in religiösem Kontext verstärkt ins Blickfeld. ${ }^{38}$ Diese zeitliche Verzögerung ist umso bemerkenswerter, als Otto Mörtzsch bereits 1921 in seiner Arbeit über die Dresdner Hoftrompeter explizit auf diesen Tätigkeitsbereich der königlich-sächsischen Trompeter und Pauker eingegangen war. ${ }^{39}$ Allerdings bleibt seine Darstellung merkwürdig diffus, denn er unterscheidet nicht scharf genug zwischen jenen großbesetzten Musikstücken, in denen neben zahlreichen anderen Instrumenten auch Trompeten und Pauken Verwendung fanden - u. a. erwähnt er „Hasse und andere Kirchenkomponisten“, die „in ihren Schöpfungen beiden Instrumenten den ihnen gebührenden Platz“ einräumten -, und der Musik, die von Trompeten und Pauken allein ausgeführt wurde: Intraden, Trillos, Aufzüge und die Begleitung der Messe (d. h. die Bekräf-

S. 117-129; Sabine ZaK, Das Tedeum als Huldigungsgesang, in: Historisches Jahrbuch 102 (1982), S. 1-32; Detlef Altenburg, Instrumentation im Zeichen des Hofzeremoniells. Bemerkungen zur Verwendung der Trompete im Schaffen von Johann Joseph Fux, in: Bernhard Habla (Hg.), Johann Joseph Fux und die barocke Bläsertradition. Kongreßbericht Graz 1985 (Alta Musica 9), Tutzing 1987, S. 157-168.

37 RiePe, Hofmusik in der Zeremonialwissenschaft (wie Anm. 1), S. 43 f.

38 Vgl. etwa Gerhard Poppe, Das Te Deum laudamus in der Dresdner Hofkirchenmusik - liturgische und zeremonielle Voraussetzungen, Repertoire und musikalische Faktur, in: Archiv für Musikwissenschaft 63 (2006), H. 3, S. 186-214; Klaus ARINGER, Zeremonielle, liturgische und musikalische Funktionen der Trompeten und Pauken in der Kirchenmusik der zweiten Hälfte des 18. Jahrhunderts, in: Friedrich Wilhelm Riedel (Hg.), Mozart und die geistliche Welt in Süddeutschland (Kirchenmusikalische Studien 12), Sinzig 2010, S. 195-207; LaRs E. Laubhold, Die Trompeter- und Paukerkunst zur Zeit Wolf Dietrichs, in: Strategien der Macht. Hof und Residenz in Salzburg um 1600 - Architektur, Repräsentation und Verwaltung unter Fürsterzbischof Wolf Dietrich von Raitenau 1587 bis 1611/12 (Mitteilungen der Gesellschaft für Salzburger Landeskunde, 28. Ergänzungsband), Salzburg 2011, S. 577-625. Vgl. auch Laubholds Ausführungen in seinem Buch: DeRs., Magie der Macht. Eine quellenkritische Studie zu Johann Ernst Altenburgs Versuch einer Anleitung zur heroisch-musikalischen Trompeter- und Pauker-Kunst (Halle 1795) (Salzburger Stier 2), Würzburg 2009, S. 217-222. Mörtzsch, Dresdner Hoftrompeter (wie Anm. 13), S. 61-63. 
tigung des formalen Ablaufs der Liturgie). ${ }^{40}$ Damit verwischte er die Grenzen zwischen der ,ausschließlichen' und der ,gelegentlichen“ emblematisch-repräsentativen Funktion dieser Instrumente und zugleich die Grenzen zwischen den eigentlichen Hoftrompetern, die in Fortführung der alten Traditionen und Privilegien ausschließlich ihre spezifischen Instrumente verwendeten, ${ }^{41}$ und den Trompetern in der Hofkapelle, den sogenannten Kammertrompetern, die zumeist auch andere Instrumente spielten und im Ensemble vielfältig einsetzbar waren.

Die symbolhafte Bedeutung von Trompeten und Pauken in der Kirchenmusik hatte auch Sabine Henze-Döhring herausgestellt. ${ }^{42}$ Sie bezog sich dabei vornehmlich auf die Dissertation von Detlef Altenburg, ${ }^{43}$ die mittlerweile durch neuere Forschungen - vgl. die Arbeiten von Lars E. Laubhold, ${ }^{44}$ Max Röber ${ }^{45}$ und dem Verfasser $^{46}$ - auf der Basis zahlreicher, seinerzeit noch unbekannter Quellen zumindest teilweise überholt ist. In den früheren Arbeiten lag das Augenmerk zumeist auf der Größe dieser Formation und der Anzahl ihrer fest angestellten Mitglieder, die man als direktes Abbild der Bedeutung eines Hofes ansah, sowie auf der vermeintlichen emblematischen und sozialen Sonderstellung jener Musiker. Zudem hat das äußere Erscheinungsbild von Trompetern und Paukern samt ihrer Livree und den oft besonders aufwendig gestalteten Instrumenten Laien und Wissenschaftler gleichermaßen fasziniert. ${ }^{47}$ Angesichts der oben angedeuteten

40 Ebd., S. 63. Dem grundsätzlichen und erbittert ausgefochtenen Streit zwischen den Dresdner Hoftrompetern und ihren Kollegen in der Kapelle - sogenannte Kammertrompeter - widmet Mörtzsch ganze zwei Sätze.

41 Vgl. hierzu Christian Ahrens, „Intraden, Trillos und Aufzüge“. Zur Funktion der Dresdner Hoftrompeter für die repraesentatio majestatis bis 1918, in: Symbole, Zeremonielle, Rituale. Wirken und Wirkung von Militärmusik bei staatlicher Repräsentanz und hoheitlichen Anlässen (Militärmusik im Diskurs 8), Bonn 2013, S. 49-70, hier S. 52 und S. 61-63.

42 Vgl. Henze-Döhring, Musik im höfischen Zeremoniell (wie Anm. 4), S. 28 f.

43 Altenburg, Geschichte der Trompete (wie Anm. 19).

44 Laubhold, Magie der Macht (wie Anm. 38).

45 Max Röber, Zur Problematik der Begriffsbildung der „Trompeter und Paukerzunft“, Bachelorarbeit an der Hochschule für Musik Carl Maria von Weber, Dresden 2010.

46 Christian Ahrens, Fiktion und Realität. Die Privilegien der Trompeter und Pauker, in: Archiv für Musikwissenschaft 68 (2011), H. 3, S. 227-255 und H. 4, S. 319-335.

47 Es sei darauf hingewiesen, dass es quasi zum Zeremoniell gehörte und vielfach üblich war, Mohren als Pauker einzustellen; vgl. hierzu Konrad Neefe, Die Entwicklung der kur- und königl. sächsischen Infanteriemusik. Von den ältesten Zeiten bis Ende des XVIII. Jahrhunderts, in: NASG 18 (1897), S 109-125, hier S. 113. Quellen vom Dresdner Hof (vgl. HStA Dresden, Oberhofmarschallamt K II, Nr. 13, Hofbuch von 1733 bis 1742) belegen übrigens, dass zumindest einige der farbigen Scholaren höher besoldet wurden als ihre Kollegen. Beim berühmten Sächsischen Campement von 1730 wirkten nicht weniger als 24 farbige Pauker mit; vgl. Das Königl. Polnische und Churfürstl. Sächsische Feld=Lager, oder Diarium und eigentliche Beschreibung alles desjenigen, was in dem grossen Campement, bey Radewitz an der Elbe, unfern Mühlberg in Sachsen, vom 31. Maji biß 27. Junii 1730. von Tage zu Tage vorgegangen, o.O. 1730, S. 7. LÜNING, Theatrum Ceremoniale Politicum (wie Anm. 30), Bd. 2, S. 1170, berichtete, dass beim sogenannten Kopff=Rennen am Wiener Hof anno 1662 neben den ,gewöhnlichen' Trompetern zwölf weitere mitwirkten, die als Mohren verkleidet waren und allesamt das Gesicht und die Hände gefärbt hatten. 
neuen Erkenntnisse erscheint es freilich geboten, die repräsentative Funktion auf der musikalischen Ebene genauer zu betrachten, die Quellen systematisch zu studieren und die gängigen Vorstellungen zu hinterfragen. ${ }^{48}$

Vorausgeschickt sei die Bemerkung, dass es im Verlauf unserer Überlegungen nicht um die Kirchenmusik im eigentlichen Sinne des Wortes gehen wird, obschon diese zweifellos erheblich zur Repräsentation der Macht beizutragen vermag. Im Zentrum wird vielmehr die ,Musik' zum Te Deum und deren, je nach zeremoniellen Erfordernissen, unterschiedliche Art der Realisierung bzw. Einbettung in andere zielgerichtete Aktivitäten stehen. $\mathrm{Ob}$ und inwieweit es sich um eine musikalische Mitwirkung im eigentlichen Sinne des Wortes handelte, etwa durch Begleitung des Gemeindegesanges oder gar dessen melodische Unterstützung, muss hier offen bleiben. Diese wäre vor 1800, zu Zeiten der Naturtrompeten, nur dann möglich gewesen, wenn zumindest einige Trompeter in der Clarinlage geblasen hätten; dafür gibt es jedoch keinen Beleg. So ist eher an fanfarenmäßige Eröffnungs- und Schlussklauseln zu denken. Dass beispielsweise die Dresdner Hoftrompeter das Te Deum melodisch unterstützten, ist erst für die Zeit nach 1862 belegt: Damals baten sie in einer Eingabe an das Oberhofmarschallamt um die Anschaffung von zwei Ventiltrompeten, damit selbige auch gleichzeitig in der Evangelischen Hofkirche bei vorkommenden De=Deums [sic!] und andern Feierlichkeiten mit benutzt werden können. ${ }^{49}$

Die Tradition, das Te Deum als besondere Form der Huldigung und damit des Herrschaftsanspruchs mit geeigneten musikalischen Insignien - insbesondere Trompeten und Pauken, aber auch Glocken und selbst Kanonenschüssen - auszustatten, reicht bis ins Mittelalter zurück: „Für den Klerus ist die Form der Zustimmung das Tedeum; deshalb ist in den Ordines vorgesehen, daß es im Anschluß an die Volksbefragung oder zum Abschluß der Krönungsmesse gesungen wird. Von daher erklärt sich, daß das Tedeum im Laufe der Zeit sich verbindet mit dem Klang der Glocken, der Orgel, der Trompeten und mit dem Donner der Kanonen; bei entsprechenden Gelegenheiten ist es der liturgische Gesang mit dem größten Aufwand an Lautstärke.“50

Zunächst fungierte das Te Deum „als Gesang zum Ende von Wahlen und Investituren“ und diente „als rechtliche Bekräftigung und akklamatorische Zustimmung“; zudem erklang es „zum Abschluss von Konzilien und Synoden, zur

48 Die katholische Kirchenmusik, die zumindest für das Herzogtum Sachsen-Weimar weitgehend ohne Bedeutung war, bleibt in unserem Kontext unberücksichtigt. Eine ausführliche Darstellung der Gegebenheiten in der Dresdner katholischen Hofkirche findet sich bei: Ahrens, Intraden, Trillos und Aufzüge (wie Anm. 41).

49 HStA Dresden, Oberhofmarschallamt K XII, Nr. 19c, Acta des Königlich Sächsischen Oberhofmarschall=Amtes, Hoftrompeter und Hofpauker betr. 1852-1918, fol. 54r/v, hier fol. 54r, Datum des Schreibens: 17. August 1862.

50 Sabine ZaK, Musik als ,Ehr und Zier' im mittelalterlichen Reich. Studien zur Musik im höfischen Leben: Recht und Zeremoniell, Neuss 1979, S. 11. 
Ehrung von Heiligen und hochgestellten Persönlichkeiten". ${ }^{51}$ Allmählich übernahm das Te Deum weltliche Funktionen und avancierte in gewissem Sinne zu einer Staatsmusik.52 Damit wurde es zu einem wesentlichen Sinnbild der zeremoniellen Darstellung politischer Macht: „Spätestens im 17. Jahrhundert hat sich die Säkularisierung der Verlagerung endgültig vollzogen: das Te Deum wird zum Sinnbild der göttlichen Legitimation des absolutistischen Fürsten. Das Anstimmen dieses Hymnus macht nunmehr einen Teil des höfischen Zeremoniells aus; es ist nicht mehr ein gemeinschaftlicher Akt der Rechtsbekräftigung, sondern wird von einer weltlichen Autorität angeordnet und von ihren Bediensteten gestaltet und ausgeführt. “53

Dabei erstreckte sich die funktionale Spannweite von prunkvollen Gottesdiensten zu hohen geistlichen Feiertagen oder zu Festtagen hochgestellter herrschaftlicher Persönlichkeiten über Jubelfeste aufgrund besonderer politischer oder gesellschaftlicher Ereignisse bis hin zu Siegesfeiern anlässlich militärischer Entscheidungen. So heißt es beispielsweise im Artikel "Te deum Laudamus" des Zedler-Lexikons: Wir pflegen ibn ordentlich bey uns an den Apostel=Tagen und Reformations=Fest des seel. Lutheri, ingleichen bey allen ausserordentlichen Solemnitäten zu singen; als wenn ein Danck=Fest, Friedens=Fest und andere Jubel=Feste ausgeschrieben sind, oder auch, wenn nach angetretener Regierung eines neuen Landes=Vaters die Huldigungs=Predigt gehalten wird, ingleichen bey Investirung der Superintendenten, und Pastoren, desgleichen bey Promotionen der Doctoren auf der Universität, zu der Zeit, wenn nach geendetem Actu die Prozeßion nach dem Altar geschiehet, den Priesterlichen Seegen zu empfangen. ${ }^{54}$

Erstaunlicher Weise fehlt der Hinweis auf die Funktion des Te Deum Laudamus bei der Festgestaltung von militärischen Siegesfeiern. Dass gerade sie Anlass gaben zur Entstehung zahlloser Kompositionen, die bis heute einen festen Platz im Repertoire einnehmen, erscheint auf den ersten Blick merkwürdig, doch ist die Erklärung, die Koldau gibt, durchaus einleuchtend: „Dies gründet in dem Glauben, dass die Entscheidung, deren Ausgang besungen wird, mit Gottes Hilfe gefallen ist. Das Te Deum erscheint als Lob und Dank an Gott, als Annahme des göttlichen Willens und als akklamatorische Anerkennung des Gewählten bzw. des Siegers." ${ }^{55}$

Einschränkend bleibt freilich festzuhalten, dass bei diesen Überlegungen lediglich vom Sieger einer Schlacht oder eines Krieges die Rede ist, nicht aber vom jeweiligen Verlierer, obschon doch auch er in der Regel davon ausgeht, dass die

51 Linda Maria Koldau, Frauen - Musik - Kultur. Ein Handbuch zum deutschen Sprachgebiet der Frühen Neuzeit, Köln 2005, S. 480.

52 ZAK, Das Tedeum (wie Anm. 36), S. 2.

53 Koldau, Frauen - Musik - Kultur (wie Anm. 51), S. 481, Anm. 469.

54 Artikel: Te Deum Laudmus, in: Zedler Lexikon, Bd. 42 (1744), Sp. 524-553, hier Sp. 538; es handelt sich um ein Zitat aus den Leichpredigten von Johann Benedikt Carpzov.

55 Koldau, Frauen - Musik - Kultur (wie Anm. 51), S. 481, Anm. 468. 
Entscheidung in der Auseinandersetzung „mit Gottes Hilfe“ gefallen ist, und obgleich auch der Unterlegene den „göttlichen Willen“ - notgedrungen - zu respektieren hat. Eine der wesentlichen Ursachen dafür, dass den Verlierern nicht nach der Ausführung des Te Deums zumute war, dürfte darin liegen, dass sich im Laufe der Zeit eine besondere Aufführungspraxis dieser Staatsmusik herausgebildet hat, in der Trompeter und Pauker, die nach Lars E. Laubhold „nur scheinbar eine normale musikalische Tätigkeit" ausübten, ${ }^{56}$ eine besondere Stellung einnahmen: „Trompeter machen keine Musik in herkömmlichem (heutigem) Sinn; Trompetenmusik ist eine Kulturtechnik, die stärker als andere Musiken zeremoniell gebunden und mit weit über unterhaltende oder emblematische Funktionen hinausgehenden Bedeutungen geladen ist. Als Teil höfischer Repräsentationsapparate künden die Trompetenensembles nicht allein von der Macht der Fürsten - sie generieren Macht. " 57 Unter diesem Gesichtspunkt verbot es sich denn wohl doch, den Verlust einer Schlacht oder eines Krieges mit eben jenen musikalischen Insignien zu begehen, die traditioneller Weise zur Feier eines strahlenden Sieges verwendet wurden.

Es war offenkundig die dezidierte Machtsymbolik, die dazu führte, dass die Tradition des feierlichen Te Deums in den protestantischen Gottesdienst ${ }^{58}$ soweit er als höfische Repräsentations-Veranstaltung diente - übernommen wurde. In Bezug auf die Situation in Dresden findet sich bei Mörtzsch nur eine sehr knappe, pauschale Information: „[...] in der evangelischen Hofkirche übten sie [i. e. Hoftrompeter] nur an besonderen Festtagen auf Befehl des Oberhofmarschalls im Einvernehmen mit dem Oberhofprediger (Choralbegleitung und Tedeum) ihre Kunst aus. "59 Inwieweit die Hoftrompeter, die bei ihren zeremoniellen Diensten Naturtrompeten bliesen, tatsächlich die Choralbegleitung übernehmen konnten (das dürfte eher Sache der Kapelltrompeter gewesen sein), bleibt offen. Für die Ausschmückung und festliche Umrahmung des Te Deums waren jedoch diese Instrumente bestens geeignet, zumal dann, wenn sie nach Art der Feldstücke mit entsprechender Blastechnik gespielt wurden, 60 die zu einer viel größeren Lautstärke führte, als sie beim ,normalen' Musizieren üblich war.

56 Laubhold, Trompeter- und Paukerkunst (wie Anm. 38), S. 582.

57 Ebd., S. 583 f.

58 Natürlich hatte das Te Deum auch seinen Platz in der katholischen Liturgie; vgl. beispielsweise zur Situation im süddeutsch-österreichischen Raum: ARINGER, Trompeten und Pauken in der Kirchenmusik (wie Anm. 38), S. 203 f.; zur Situation in Dresden: Poppe, Te Deum laudamus (wie Anm. 38).

59 Mörtzsch, Dresdner Hoftrompeter (wie Anm. 13), S. 63.

60 Vgl. Andreas Lindner, Die kaiserlichen Hoftrompeter und Hofpauker im 18. und 19. Jahrhundert (Wiener Veröffentlichungen zur Musikwissenschaft 36), Tutzing 1999, S. 826, Anm. 3280: „Da der Feldtrompeter die Signale mit größtmöglicher Lautstärke und auch während des Reitens zu spielen hatte, mußte er über eine spezielle Atemtechnik verfügen, die sich sehr häufig negativ auf die Flexibilität, die Klangkultur und die Intonation auswirkte.“ 
Mit dem Übertritt des sächsischen Kurfürsten Friedrich August I. zum katholischen Glauben ergaben sich logistische Probleme im Hinblick auf die Koordinierung der Ausführung des Te Deums. Denn: Weilte der König in Dresden und wohnte dem Te Deum in der katholischen Hofkirche bei, mussten „die üblichen Geschützsalven mit dem dort gesungenen Hymnus abgestimmt werden. “61 $\mathrm{Zu}$ gleich aber war es erforderlich, dass der Hof diese Aktivitäten mit dem Ablauf des Ritus in den evangelischen Kirchen der Stadt koordinierte. Die Geburt des Thronfolgers Prinz Friedrich August am 18. November 1720 beispielsweise wurde am darauf folgenden Sonntag mit einem Te Deum begangen: „Schließlich wurde das Te Deum um halb zwölf in beiden Hof- und allen Stadtkirchen gleichzeitig gesungen und dabei von den üblichen Geschützsalven sowie dem Geläut aller Glocken begleitet." 62

Man muss sich vergegenwärtigen, dass diese zeremonielle Bündelung von Einzelaktionen eine logistische Herausforderung darstellte. Denn es galt nicht nur, eine protokollarisch-liturgische Abstimmung zwischen den Kirchen beider Konfessionen und den verschiedenen zuständigen Hofämtern herbeizuführen, ${ }^{63}$ sondern darüber hinaus sicherzustellen, dass die Aktivitäten an den unterschiedlichsten Orten zeitgleich ablaufen konnten. Immerhin mussten die Geschützsalven mit Eintritt eines bestimmten Textabschnittes abgefeuert werden: „Die Erste unter den Worten: Heilig, Heilig, Heilig, die andere: Täglich HERR Gott etc." Die Bindung der Salven an einzelne Textworte blieb „dem Te Deum vorbehalten und unterstreicht dessen Sonderstellung nicht nur bei besonderen Anlässen, sondern auch innerhalb der regulären liturgischen Praxis."64

Eine ähnliche Verbindung von Text, Musik und zeremoniellen Geräuschen bestimmte auch die Einweihung von Schloss und Kirche zu Friedrichswerth nahe Gotha im Juli 1689. Das Zeremoniell legte für den Ablauf des Gottesdienstes unter Punkt 15 fest: Herr Gott dich loben wir etc. mit Trompeten, Paucken undt Stücken

61 Poppe, Te Deum laudamus (wie Anm. 38), S. 194.

62 Ebd., S. 195 (Hervorhebung original). Das Te Deum im Rahmen der Festivitäten zum Einzug der Gemahlin des sächsischen Erbprinzen 1719 in Dresden wurde noch pompöser begangen: Zusätzlich zum Klang der Trompeten und Pauken sowie dem Geläut der Glocken wurden nicht weniger als 110 Kanonen abgefeuert; Accurate Beschreibung des solennen Einzugs Ihrer Hoheit des Königl. Pohln. und Chur=Prinzen von Sachßen, mit seiner aus Wien angekommenen Durchl. Gemahlin [...], Dresden [1719], S. [15].

63 Poppe, Te Deum laudamus (wie Anm. 38), S. 196.

64 Ebd., S. 189 (Hervorhebung original). Ein Bericht aus Leipzig über die Gottesdienste anlässlich des Übertritts des sächsischen Kurfürsten zum katholischen Glauben 1697 bestätigt die enge Verbindung des Te Deums mit Kanonen- und Gewehrschüssen; auch hier dürfte die Koordinierung der verschiedenen Aktivitäten nicht gerade einfach gewesen sein. Vgl. Johann Jaсов Vogel, Leipzigisches Geschicht=Buch oder Anales, das ist: Jahr= und Tage=Bücher der weltberühmten Königl. und Churfürstl. Sächsischen Kauff $=$ und Handels=Stadt Leipzig [...], Leipzig 21765, S. 901 (24. Mai 1697): [...] [daß] auf ergangenen Königlichen Befehl in allen Kirchen [Leipzigs] allhier nach der Predigt das Te Deum laudamus gesungen, die Canonen auff der Vestung gelöset, und von einer Compagnie Soldaten, die an der Thomas=Kirche rangiret waren, drey mabl Salve gegeben wurde. 
[i. e. Kanonen], undt zwar werden ordentlich beÿm Singen 2. Clarine mit geblasen, (2.) beÿ den Wortten: Herr Gott wir dancken dir etc: werden alle Trompeten geblasen, auch die Stücke das erste mabl gelöset. (3.) Bë̈ den Wortten: Loben dich Herr mit großem Schall, abermabl alle Trompeten [1t. Aufstellung mindestens 18, meist von fremden Höfen; dazu 2 Pauker] undt die andere Salve mit Stücken. (4.) Wenn Amen gesungen wird, Laßen sich wieder alle Trompeten hören, die Stücke aber nicht. .5

Quellen aus Weimar liefern ebenfalls anschauliche Belege für die Bedeutung, welche dem Te Deum für die Repräsentation zukam, und dafür, wie strikt dessen Ausführung festgelegt war. Sie zeigen, dass der Einsatz von Trompeten und Pauken, wie der der übrigen musikalischen oder jedenfalls akustischen Klangmittel, einem stringenten Reglement folgte, das seinerseits streng hierarchisch abgestuft war.

Die ,unterste ${ }^{`}$ Klasse der Instrumentalbesetzung beim Te Deum, ohne Trompeten und Pauken, war z. B. für feierliche Gottesdienste zu Ehren nicht regierender Angehöriger einer fremden Fürstenfamilie vorgesehen. So heißt es im Bericht des Weimarer Fourierbuchs vom 4. Januar 1749: Der Geburtstag der Prinzessin Auguste von Bayreuth wurde nicht bë̈ Hofe celebriret, sondern in der Kirche den Sonntag darauf, das Te Deum laudamus doch obne Trompetten und Paucken gesungen. ${ }^{66}$ Ebenso verfuhr man am 11. Mai 1749 anlässlich des Geburtstages der Fürstin von Rudolstadt.

Die ,höchste ' Klasse, mit Trompeten und Pauken (vermutlich auch mit Glockengeläut), blieb Regenten sowie Angehörigen der jeweiligen Herrscherfamilie vorbehalten. In einem Bericht der Weimarischen Wöchentlichen Anzeigen vom 28. Oktober 1772 ist zu lesen: Am vergangenen Sonnabend, den 24. d. M., hatten die Ober Vormundschaftl. Lande, Sachsen Weimar, Eisenach, Jena die ganz ungemeine Freude, der Durchlauchtigsten Fürstin und Frau, Frauen Annen Amalien, verwittibte Herzogin zu Sachsen, [...] unserer gnädigsten Fürstin und Frauen böchstes GeburtsFest zum 33sten mable, [...] feyerlich begehen zu können. [...]. An dem darauf gefolgten Sonntage wurde Gott in seinen Vorböfen das Lob=und Dankopfer öffentlich dargebracht, das Te Deum Laudamus unter Trompeten und Paukenschall abgesungen und in der Hofkirche besonders eine Kirchenmusik von der ausnebmenden Composition des Herrn Capellmeisters Wolf aufgeführet. ${ }^{67}$

Und ein Eintrag vom 16. Oktober 1757 im Weimarer Fourierbuch berichtet über die Zeremonien bei einem Gottesdienst-Besuch der Herzogin in der Schlosskirche: Wegen dieser Woblthat wurde das Te Deum Laudamus unter Trompeten und Paucken Schall gesungen: Nachbero mit diesen zur Tafel geschlagen und

65 Thüringisches Staatsarchiv Gotha, Geheimes Archiv E. XI. 52a, Hochfürstl. Geburtstagfeÿer den 16. Julÿ Einsegnung des Fürstl. Schloßes und der Kirche zu Friedenswerth den 19 Julÿ 1689 , fol. 35 .

66 HStA Weimar, Hofmarschallamt Nr. 4501, Fourierbuch 20. Januar 1748 bis 27. Oktober 1749, fol. 47r (S. 95).

67 Weimarische Wöchentliche Anzeigen, Nr. 87, 20. Oktober 1772, S. 357 f. 
geblasen: Während der Tafel Music gemacht, die Gesundheiten unter Trompeten und Paucken Schall getruncken u. Abends war Assemblee und speiseten nachstebende Hobe Personen an 4 Tafeln, während diesen ward Music gemacht. 68

Aber auch Feierlichkeiten zum Geburtstag des Erbprinzen oder der Verlobung des Herzogs wurden mit entsprechendem musikalischen Pomp ausgestaltet: Heute nach der Früh=Predigt wurde die Bekanntmachung wegen Verlobung Unsers Durchl: Herzogs, Carl August, mit der Durchl: Prinzeßin Louise von Heßen Darmstadt von allen Kanzeln verleßen, welches jedermann zu großer Freude geschabe. Nach der Verlesung wurde das te deum laudamus unter Trompeten und Paucken Schall gesungen. Und weil Durchl: Herzogin in die Stadt Kirche zum Gottesdienst fubren, befablen Dieselben gnädigst: daß die Hof=Trompeter solten in der Stadt Kirche blasen, und die Stadt Musicanten das Te deum laudamus in der Hof Kirche zu S. Jacob. Gestern wurde durch den Hof Fourier beÿ Hofe auf beute Galla angesagt, und obige Tafel Mittags 2 mal serviret. Abends war Assemblée und an 2 Tafeln gespeißet. Webrender Mittags Tafel war Concert mit Trompeten und Paucken. ${ }^{6}$

Bemerkenswert ist die Tatsache, dass neben den Hoftrompetern in der Stadtkirche (sie war das geistliche Zentrum für den Weimarer Hof) auch die Stadtmusiker in der Kirche St. Jacob das Te Deum Laudamus spielen sollten - mit Sicherheit ebenfalls unter Verwendung von Trompeten und Pauken. Somit erfüllten beide Formationen, die im Allgemeinen getrennt agierten, mit den gleichen Instrumenten und in musikalisch wie zeremoniell vergleichbarer Weise ihre symbolhafte Funktion: an getrennten Orten zwar, doch im Rahmen einer als Einheit gedachten großen Zeremonie.

Dass die Mitwirkung beim Te Deum noch bis 1918 zu den wichtigsten Funktionen der Dresdner Hoftrompeter zählte, lässt sich dem Dienstvertrag des neu eingestellten Hoftrompeters Friedrich Reinhold Burkhardt (1885-1955) vom 18. Juni 1914 entnehmen. Dort heißt es in $\mathbb{\$}$ 3: Bei den katholischen Hof-Gottesdiensten haben sie [i. e. Hoftrompeter] den Anordnungen der königlichen Kapellmeister Folge zu leisten, sowie vorkommenden Falls beim evangelischen Hof-Gottesdienste die Trompeten- und Paukenbegleitung des Tedeum zu übernebmen. ${ }^{70}$

68 HStA Weimar, Hofmarschallamt Nr. 4505, Fourierbuch 11. September 1757 bis 30. Juni 1758, fol. 36v (S. 39).

69 HStA Weimar, Hofmarschallamt Nr. 4524, Fourierbuch 1. Januar bis 31. Dezember 1775, fol. 21 (S. 22), Datum: 5. Februar 1775.

70 HStA Dresden, Oberhofmarschallamt K XII, Nr. 19c, fol. 139a/r-139b/v, hier fol. $139 \mathrm{a} / \mathrm{v}-139 \mathrm{~b} / \mathrm{r}$. Burkhardt war von 1911 bis zu seiner Einstellung am Hofe Erster Trompeter (Solist) beim 2. Grenadier-Regiment „Kaiser Wilhelm, König von Preußen“. Für Informationen über Burkhardt danke ich Herrn Torsten-Pieter Rösler, Kunstgewerbemuseum, Staatliche Kunstsammlungen Dresden. Zu Burkhardts Dienstobliegenheiten vgl. Christian Ahrens, Hautboisten versus Trompeter. Der Streit unter den Militärmusikern im 18. Jahrhundert und seine Folgen, in: Michael Schramm (Hg.), Popularisierung und Artifizialisierung in der Militärmusik (Militärmusik im Diskurs 7), Bonn 2012, S. 34-60, hier S. 54-56. - Laut dem Grimmschen Wörterbuch (Deutsches Wörterbuch von Jacob und Wilhelm Grimm, Artikel: Trompetenbegleitung; Internet- 
Was im evangelischen Gottesdienst das Te Deum, waren im katholischen Gottesdienst der Dresdner Hofkirche die sogenannten Intraden, Trillos und Aufzüge. Sie bestanden teils aus nicht notierten melodischen Floskeln - auf der Grundlage eines aus der Struktur der Naturtonreihe erwachsenen ,Fanfarenmelos ${ }^{\varsigma}$-, teils aus improvisierten Abschnitten. Auch diese Signale hatten nichts mit der Kirchenmusik im eigentlichen Sinne zu tun, sondern dienten allein der repraesentatio majestatis. Konsequenter Weise ging es daher nicht um die Demonstration herausragender virtuoser Fähigkeiten - etwa durch ein Musizieren in der Clarinlage -, oder die Ausführung ausgefeilter, anspruchsvoller Kompositionen, sondern allein um die symbolhafte Darstellung der Macht des sächsischen Königs. Und die wurde befördert durch die noch immer zur Ausstattung gehörenden Livreen, welche die Trompeter und Pauker trugen, die äußere Aufmachung der kostbaren Naturtrompeten und der Pauken, sowie, nicht zuletzt, die Lautstärke, mit der die Signale bzw. Fanfaren dargeboten wurden. ${ }^{71}$

\section{Militärmusik - Die Janitschareninstrumente}

Es lässt sich nicht genau sagen, wann man in Weimar die Janitscharenmusik einführte. Der früheste bisher bekannt gewordene Beleg für die Existenz entsprechender Instrumente in Eisenach datiert von 1729: Es handelt sich um das Musikinstrumenten-Inventar nach dem Tode des Herzogs Johann Wilhelm (16661729) von Sachsen-Eisenach. ${ }^{72}$ In den Schatullrechnungen des Weimarer Herzogs Ernst August I. (1688-1748; reg. 1728-1748) findet sich unter dem Datum des 1. Dezember 1746 der Eintrag, dass an den Musicus Johann Ludwig Geyer 14 Thlr. 16 Gr. vor Türckische Instrumente gezahlt wurden. ${ }^{73}$ Am 1. Mai 1747 erhielt der Cammer Musicus Christoph Friedrich Gejer in Meiningen 12 Thlr. vor allerhand Janitscharen Instrumente, die er nach Eisenach geliefert hatte. ${ }^{74}$ Die von Johann Ludwig [sic!] Geÿer ${ }^{75}$ unterzeichnete Quittung enthält eine handschriftliche

version http://woerterbuchnetz.de/DWB; Zugriff am 4. November 2012) wurde in Kiel die Mitwirkung von Trompeten und Pauken beim Te Deum 1834 nur noch an den drei höchsten Feiertagen praktiziert.

71 Vgl. Ahrens, Intraden, Trillos und Aufzüge (wie Anm. 41).

72 HStA Weimar, Kunst und Wissenschaft - Hofwesen A 9275, fol. 7r-8v, Datum: 19. Februar 1729. (1741 fiel das bis dahin selbstständige Herzogtum Sachsen-Eisenach an Sachsen-Weimar.) In Preußen wurde die Janitscharenmusik 1740 eingeführt (vgl. Ludwig Degele, Die Militärmusik, ihr Werden und Wesen, ihre kulturelle und nationale Bedeutung, Wolfenbüttel 1936, S. 112) und damit zwei Jahrzehnte später als in Kursachsen. Die sächsischen bzw. polnischen Janitscharen spielten unter zeremoniellen Aspekten beim Sächsischen Campement von 1730 (siehe unten) eine bedeutende Rolle.

73 HStA Weimar, Fürstenhaus A 891, Schatullrechnungen Ernst August I., Juni bis Dezember 1746, fol. 829.

74 HStA Weimar, Fürstenhaus A 892, Schatullrechnungen Ernst August I., Januar bis Juni 1747, fol. 367.

75 Johann Ludwig Geyer (1695-1754) war am Meininger Hof erst Fagottist, dann Waldhornist. Zum 1. Juli 1734 wechselte er als Waldhornist an den Weimarer Hof, kehrte jedoch bereits Anfang Januar 1735 nach Meiningen zurück. Vgl. Maren Goltz, 
Ergänzung des Weimarer Kanzlisten Johann August Rost: Obige 12 rthlr. sind vor die Janitscharen Musicalien welche ich noch bey mir in verwabrung babe und in 5 Partien besteben. ${ }^{76}$

Dass es in Weimar Janitscharenmusik bereits vor 1746 gegeben hat, ist demnach wahrscheinlich, jedoch quellenmäßig nicht zweifelsfrei zu belegen. Es spricht jedenfalls einiges für die Annahme, dass Herzog Ernst August I. wesentliche Anregungen zur Nutzung einer Janitscharentruppe beim Campement von 1730 erhielt. Auf Einladung des sächsischen Kurfürsten hatte er an diesem Evenement teilgenommen und mehrere Formationen Soldaten geschickt (alle aufs Beste ausgerüstet); Janitscharen sind in diesem Zusammenhang nicht erwähnt. ${ }^{77}$ Dass die Janitschareninstrumente bei den Hautboisten-Banden, also bei den MilitärmusikFormationen, zum Einsatz kamen, ist sicher, doch vermitteln die bislang mitgeteilten Quellen keine weiteren Informationen.

Interessante Aufschlüsse verdanken wir einem Dokument vom Anfang des Jahres 1782. Damals suchte der frühere Regiments-Hautboist und nachmalige Hofmusiker Johannes Edeling beim Hofmarschallamt um eine Vergütung für den Unterricht nach, den er auf herzoglichen Befehl einigen Soldaten auf den Janitschareninstrumenten erteilte. Aufgrund dieses Gesuchs erbat die KriegsKommission nähere Informationen, ${ }^{78}$ und so fand am 22. Februar 1782 eine Befragung des Supplikanten statt.

Der gab an, bereits im Jahre 1777 [...] hätte Serenissimus, als Höchstdieselben die Janitscharen Music sebr schlecht befunden, ibm auf der Ober Weimar[ischen] Wiese beÿm Excerciren gnädigst anbefoblen, für beßere Zusammenstimmung und sonst denen zu gedachter Music gehörigen Personen möglichst zu ertheilenden Unterricht zu sor=gen, für welche Bemühung ibm zugleich monatlich Ein Thaler aus Fürstl. Kriegs=Caße wäre gnädigst ausgesetzet worden. Er babe seinerseits diesem Höchsten Befehl möglichst nachzukommen gesuchet, së̈ mit bemeldten Leuten zur Sommerzeit fast alle Wochen wenigstens einmahl außer der Stadt gegangen, habe sie zusammen auf ibren Instrumenten geübt, verschiedene Parthieen für sie componiret und auch andere abgeschrieben. Viele Aergerniß und Mübe habe ihm dieses verursachet, weil er den meisten besagter Leute, welche theils die Noten nicht verstehen, theils nicht verstehen lernen wollen, nur etwas nach dem

Musiker-Lexikon des Herzogtums Sachsen-Meiningen (1680-1918), Meiningen 2012, S. 111 f.; Internetversion: http://www.db-thueringen.de/servlets/DerivateServlet/Derivate-24956/goltz_musikerlexikon_3.pdf (Zugriff am 29. August 2012).

76 HStA Weimar, Fürstenhaus A 892, Schatullrechnungen Ernst August I., Januar bis Juni 1747, fol. 367b, Datum: 4. Mai 1747. Die Quittung wurde in Eisenach ausgestellt.

77 Vgl. Karl Helmrich, Geschichte des Großherzogthums Sachsen-Weimar-Eisenach für Schule und Haus, Weimar 1852, S. $108 \mathrm{f}$.

78 HStA Weimar, Militärwesen B 38622, Das an den Regiments Hautboisten, Johannes Edeling alhier, für den Unterricht der zur Janitscharen Musick, bestellten Personen abzugebende Honorarium betr. 1782, Datum der Bitte um Information: 20. Februar 1782 . 
Gehöre beÿbringen müßen. Von dem ihm dafür huldreichst verwilligten Emolument aber së̈ ibm bisher noch gar nichts verabreicht [...].

Er, Deponent, werde sich dieserbalb gerne noch länger gedulden, wenn ihm nicht seine vorjährige langwierige Krankheit und andere Umstände viele beträchtliche Ausgaben, die er erst noch größtentheils bestreiten müße, verursachet bätten. Er sehe [sich] daher nothgedrungen, Hochfürstl. Kriegs=Commission um baldige Hohe Verfügung, da ihm das von Serenissimo, in Gegenwart des Herrn Obristen von Lasberg und Herrn Lieut. von Hönning, mildest geordnete Emolument, vom Jabre 1777. an, aus Fürstl. Kriegs=Caße ausgezablet werden, andurch unterthänig zu bitten.

Nachrl:

J[ohann] G[eorg] Seeger [Kriegskanzlist] $]^{79}$

Dem Bericht ist zu entnehmen, dass der Herzog persönlich sich um die Qualität der Janitscharenmusik bekümmerte, sie 1777 für schlecht befand und Edeling befahl, die entsprechenden Leute - von Musikern im eigentliche Sinne wird man kaum sprechen können - zu unterrichten. Dass dem Hautboisten dafür tatsächlich ein Honorar von einem Taler monatlich in Aussicht gestellt worden war, scheint angesichts der Zeugen, die Edeling namentlich aufführte, sicher. Ob sich der Herzog allerdings bewusst war, dass dieser Unterricht auf Jahre hinaus erteilt werden sollte, erscheint fraglich. Immerhin erkannte die Hofverwaltung an, dass die Ausbildung zeitraubend war und angesichts der vom Antragsteller beklagten fehlenden musikalischen Kenntnisse seiner ,Schüler' über längere Zeit hinweg fortgeführt werden musste. So wurde entschieden, Edeling für die zurückliegenden fünf Jahre (pro praeterito) insgesamt 30 Thlr. auszuzahlen, und ihm zugleich für die Zukunft (pro futuro/künftighin) ein Gulden [2/3 Taler] monatlich [8 Taler jährlich] bewilligt. ${ }^{80}$

Edelings Ausführungen enthalten einige bemerkenswerte Informationen. Zum einen, dass der Hautboist mehrere Stücke für diese Besetzung komponiert und weitere abgeschrieben hatte. Es existierte mithin in Weimar ein Repertoire an Janitscharenmusik, keineswegs wurden einige wenige Stücke bei allen Gelegenheiten wiederholt. Zum anderen, dass die Soldaten, die er zu unterrichten hatte, theils die Noten nicht verstehen, theils nicht verstehen lernen wollen, sodass er ihnen nur etwas nach dem Gehöre bë̈bringen müßen. Diese Feststellung ist für uns heute einigermaßen befremdlich. Man muss sich jedoch der Tatsache bewusst sein, dass beispielsweise die Mehrzahl der privilegierten Trompeter selbst nach 1800 nicht über Notenkenntnisse verfügte, sie demzufolge alle Repertoire-Stücke auswendig spielten, ohne dass es deswegen in ihrem spezifischen Einsatzbereich zu Problemen gekommen wäre. Einem Hautboisten hingegen musste dieser

79 HStA Weimar, Militärwesen B 38622, fol. 3r-4 r. Seit den 1730er-Jahren legte man in Weimar für den Gulden den andernorts bereits seit längerem gültigen 16 Groschenfuß zugrunde: 1 Gulden hatte nur noch 16 statt 21 Groschen und entsprach damit 2/3 statt ursprünglich $7 / 8$ Taler.

80

Ebd., fol. 6r. 
Umstand seltsam vorkommen, denn seit langem waren die Angehörigen dieses Berufsstandes des Notenlesens kundig. Aus der Unfähigkeit, Noten zu lesen, darf man freilich nicht vorschnell auf mangelnde musikalische Fertigkeiten schließen, zumal sich an der Zuständigkeit von Soldaten für die sogenannte Türkische Musik im Rahmen rein militärischer Dienste und Verrichtungen in Weimar auch in der Folgezeit nichts änderte. Hautboisten wurden nur für repräsentative Dienste ${ }^{81}$ herangezogen, und die Ausführung der Janitscharenmusik in der Oper oder in Konzerten der Hofkapelle übernahmen wenige Jahre später die Stadtmusiker. Janitschareninstrumente hatten jedenfalls in der Militärmusik des Herzogtums Sachsen-Weimar eine besondere Bedeutung - immerhin ist den Akten zu entnehmen, dass man über mehrere Instrumenten-Sätze verfügte, ${ }^{82}$ die in allen denkbaren Genres eingesetzt wurden.

Dass die Verbindung der Janitscharenmusik mit dem musikalischen Herrschaftssymbol par excellence, dem Ensemble von Trompeten und Pauken, keineswegs eine Weimarer Besonderheit darstellte, belegt eine Notiz aus Berlin vom Januar 1748 in den Leipziger Zeitungen. Dort heißt es in einem Bericht über die Feierlichkeiten anlässlich des Geburtstages des preußischen Königs Friedrich II. (1712-1786) am 24. Januar 1748, es habe zwischen fünf und sechs Uhr ein Umzug durch die Hauptstrassen stattgefunden unter dem Schall der Trompeten und Paucken, und der Janitscharen=Music. ${ }^{83}$ Und auch aus der Beschreibung des Sächsischen Campements ${ }^{84} 1730$ erhellt, welche Bedeutung diese Musiker für die Repräsentation hatten. In der Schilderung der wichtigsten Begebenheiten dieses Events hieß es im Zedler-Lexikon dazu voller Bewunderung: Voran [d. h. vor einem der Ober=Officiers] gingen vier und zwantzig85 vollkommen schwartze Mobren im weissen Band, so die Musick machten, und hinten ward mit ebenso

81 Siehe unten.

82 HStA Weimar, Kunst und Wissenschaft - Hofwesen A 9604a, Hof=Theater Directions Commissions Acta Diciplin Sachen beÿ der Herzogl. Capelle und Anordnungen überhaupt betr. Ao 1811-1852, fol. 8 r/v, Datum des Schriftstücks: 17. August 1814.

83 Leipziger Zeitungen, 29. Januar 1748, S. 67 f.

84 Im Artikel: Mühlberg (Campement bey), in: Zedler Lexikon, Bd. 22 (1739), Sp. 72-118, hier Sp. 72, wird Campement als Musterung und dabey fürgenommene Kriegs= Uebungen bezeichnet. STEFAN Kroll, Soldaten im 18. Jahrhundert zwischen Friedensstiftung und Kriegserfahrung. Lebenswelten und Kultur in der kursächsischen Armee 1728-1796 (Krieg in der Geschichte 26), Paderborn u. a. 2006, S. 216, beschreibt sie als besonders aufwendige Truppenschauen oder Lustlager, die „neben ihrem militärischen Zweck fast immer auch bewusst auf die Wirkung nach außen hin abzielten." Nach den überlieferten Schilderungen des Campements von 1730 zu urteilen, lag das Hauptziel von August dem Starken darin, den preußischen König Friedrich Wilhelm I. durch die Größe, die Aufmachung und Ausrüstung sowie die technischen Leistungen seiner Truppen und der sonstigen Entourage zu beeindrucken.

85 In einer anderen Beschreibung des Campements wird die Zahl der Mohren-Musiker mit zweimal 20 beziffert; Ausführliches und richtiges Journal, dessen, was in dem Welt=bekandten Königl. Pohln. und Churfürstl. Sächs. Lust=Campement bey Mühlberg in Sachsen [...] öffentlich vorgegangen, Magdeburg 1730, S. 22 f. 
starcker Musick geschlossen, welche bestehet in Trommeln, Schalmeyen, Paucken und meßingenen Becken. Die Trommeln sind sehr groß und schön gemachet, und werden oben nur mit einem gewöhnlichen Kleppel, unten aber mit einem Rüthgen geschlagen; die Becken, so gantz dünne, und der Form nach wie Barbier=Becken aussehen, werden Tactmäßig zusammen geschlagen, welches einen singenden Thon giebt; diejenigen so die Becken schlagen, tragen auf dem Rücken zwey kleine Paucken, so von einen [i. e. anderen Musiker] geschlagen werden. Diese gantze Africanische Music [sic!] nun machte wegen ibrer Seltenheit die aufmerksamste Zuschaner." 86

Die besondere Wertschätzung der Repräsentationswirkung von Janitscharenmusikern - deren Musik zwar fremd geklungen haben dürfte, aber der ,echten türkischen Militärmusikformation mebterbane nicht wirklich glich ${ }^{87}$ - lässt sich nicht zuletzt daran erkennen, dass die Formationen gelegentlich von den Regierenden selbst angeführt wurden (das trifft auch für August den Starken zu) ${ }^{88}$ und dass diese sich direkt und unmittelbar mit der Ausbildung und der Leistung der betreffenden Soldaten beschäftigten. Und natürlich, dass diese Formationen gelegentlich außerordentlich stark besetzt waren - was wiederum von der Finanzkraft des Herrschers abhing und diese unmittelbar in der Außendarstellung widerspiegelte; wie etwa beim Campement von 1730: „Jedenfalls aber musste die Bildung eines 600 Mann starken Janitscharen-Bataillons im Jahre 1729, welches anläßlich des berühmten Lust- und Paradelagers bei Zeithain und Radewitz (in der Zeit vom 30. Mai bis 29. Juni 1730), gleichsam als historische Verherrlichung und Gedächtnisfeier der Sachsenkämpfe mit den Türken, gefechts- und parademäßige Ecerzitien vorführte und an seiner Spitze ein aus zwanzig Mohren bestehendes Janitscharenmusikkorps besaß mit:

6 türkischen oder großen Trommeln,

3 kleinen Kesselpauken (wohl Wirbel- oder Rolltrommeln), ${ }^{89}$

4 Paar „messingenen Tellern, so sie zusammenschlugen“ (Becken) und

7 türkischen Schalmeien,

20 Mann,

einen nachhaltigen Anstoss zur allgemeineren Pflege dieser Musikgattung geben. $" 90$

86 Artikel: Mühlberg (wie Anm. 84), Sp. 85.

87 Vgl. Ralph Martin JäGer, Artikel: Janitscharenmusik, in: Die Musik in Geschichte und Gegenwart, 2. Ausgabe, Sachteil, Bd. 4, Kassel u. a. 1996, Sp. 1316-1329, hier Sp. 1324

88 Ebd., Sp. 1325.

89 Hier irrte Neefe - es handelte sich tatsächlich um kleine Kesselpauken.

90 Neefe, Sächsische Infanteriemusik (wie Anm. 47), S. 112 f. (Hervorhebungen original). $\mathrm{Da}$ die Musterung sich über eine größere Fläche erstreckte, werden in der Beschreibung des Campements unterschiedliche Ortschaften angegeben: neben Zeithain und Radewitz auch Mühlberg (siehe unten). 
Mit Sicherheit erfolgte die Aufstellung einer so großen Janitscharentruppe 1729 bereits mit Blick auf deren Wirkung beim geplanten Campement. ${ }^{91}$ Denn für den ,normalen' Gebrauch hätte selbst der sächsische Kurfürst und polnische König keine so stark besetzte Truppe benötigt. So nimmt es denn nicht Wunder, dass sie bereits 1763 aus finanziellen Gründen wieder aufgelöst wurde, nachdem sie in den 35 Jahren ihrer Existenz sicher gute Dienste bei zeremoniellen Anlässen geleistet hatte. ${ }^{92}$ Hingegen existierte die wesentlich kleinere Janitscharenformation in Weimar deutlich länger. Seit 1777 bemühte sich Herzog Carl August darum, die Leistungsfähigkeit der Truppe zu erhöhen, und noch 1782 befahl er die Weiterführung der Ausbildung der betreffenden Soldaten. Wie lange die Truppe in Weimar bestand, ist nicht genau überliefert. Zwar wurde die Bedienung der Janitschareninstrumente bei Opernaufführungen und Konzerten, wie bereits angedeutet, in den 1790er-Jahren den Stadtmusikern übertragen, doch darf man daraus nicht den Schluss ziehen, dass das Militär nicht mehr über eine Janitscharenmusik verfügte. $\mathrm{Da}$ allerdings die zuständigen Militärmusiker, wie den oben zitierten Quellen zu entnehmen ist, nicht über Notenkenntnisse verfügten, ließen sie sich zwar beim Exerzieren oder Paradieren, nicht aber in der Oper oder dem Konzert einsetzen. Der bislang letzte bekannte amtliche Beleg für die Existenz einer Türkischen $\mathrm{Mu}$ sik beim Weimarer Militär datiert von 1814. In einer Verfügung an den Kapelldiener Friedrich Emanuel Buchholz untersagte ihm die Hofverwaltung, in Zukunft die Janitschareninstrumente an den Stadtmusikus auszuleihen. Dieser müsse sie auf eigene Kosten anschaffen oder sie von der zuständigen Militärbehörde ausleihen - die verfüge nämlich über zwei Sätze. ${ }^{93}$

Welchen Eindruck die Janitscharenmusik auf die Gäste des Zeithainer Lagers von 1730 machen sollte und welche Bedeutung der sächsische Kurfürst und polnische König ihr als Repräsentationsmittel zumaß, lässt sich der Tatsache ent-

91 Allein die bautechnischen Vorbereitungen dauerten mehr als ein Jahr; vgl. HaNs Beschorner, Das Zeithainer Lager von 1730, Teil II, in: NASG 28 (1907), S. 50-113, hier S. 51; S. 53 f.; allgemeine logistische Planungen hatten bereits 1728 begonnen; ebd., S. $102 \mathrm{f}$.

92 Neefe, Sächsische Infanteriemusik (wie Anm. 47), S. 113. Nach Neefe (S. 112) hatte Kurfürst Johann Georg II. (reg. 1656-1680) in Sachsen ca. 1670 bei der Infanterie das sogenannte „Türkische [...] Päucklein mit kleinen Schalmeien“ eingeführt, das „zur Aufwartung bei größeren Hoffesten " eingesetzt wurde. Kurfürstlich-sächsische Truppen nahmen unter Johann Georg III. (reg. 1680-1691) 1683 und 1686, unter August dem Starken 1695 und 1696 am Feldzug gegen die Türken teil; vgl. Paul HaAke, Die Türkenfeldzüge Augusts des Starken 1695 und 1696, in: NASG 24 (1903), S. 134-154. Auch in Warschau bestand, noch aus der Zeit König Jan Sobieskis (1629-1696), eine Janitscharenkapelle, vermutlich erhielt August der Starke dort die Anregung zur Gründung seiner eigenen Janitscharenmusik; vgl. Alina Zórawska-Witowska, Die Folgen der Herrschaft Augusts II. für die Musikkultur Warschaus, in: Rex Rexheuser (Hg.), Die Personalunionen von Sachsen-Polen 1697-1763 und Hannover-England 17141837. Ein Vergleich, Wiesbaden 2005, S. 221-238, hier S. 227 und S. 230.

93 HStA Weimar, Kunst und Wissenschaft - Hofwesen A 9604a, fol. 8r/v, Datum: 17. August 1814. 
nehmen, dass sie entscheidenden Anteil an den zeremoniellen Veranstaltungen zum Beschluss des Campements hatte. Am letzten Tag (26. Juni; die Majestäten reisten am 27. Juni früh ab) mussten sich die Offiziere der Reihe nach im Quartier des General-Feldmarschalls versammeln und ihre jeweiligen Truppen Pelotonsweise zu Fuß vor die Königl. Zelte marchiren lassen. Jedes Regiment von der Cavallerie hatte seine Trompeter und die Infanterie Hautboisten vor, und die Tambours und Quer=Pfeiffer hinter sich. Die Truppen marschierten an der Tafel des Preuß. Königs vorbei und wurden auf dem davor liegenden Platz von sämtlichen Regimentern mit Paucken, und in 2. Theil getheilten Janitzscharen=Music, empfangen [...]. ${ }^{94}$

Über die rein musikalische Funktion der Janitscharenmusiker hinaus, die durch ihre Hautfarbe bzw. Bemalung und die pittoreske Montur unterstrichen wurde, hatten sie beim Campement 1730 weitere wichtige Aufgaben im Rahmen des Zeremoniells zu erfüllen: Sie trugen, gemeinsam mit anderen extravagant gekleideten Soldaten, im Zelt des preußischen Königs die Speisen auf: Zu Mittag speiseten beyde Majest. Majest. [sic!] nebst vielen Fürstl. Personen an einer grossen Tafel öffentlich unter Ihro Königl. Preußischen Majest. Tafel=Gezelt, darzu die Cadets und Janitzschaaren [sic!] die Speisen trugen; die Panzernen, die 6 grosse in Gold=Stück gekleidete Türcken, die 6 propres Ungarische Cavalliers, die 6 überaus ansebnliche besonders gekleidete Hayducken und 24 Mobren, nebst gewöhnlichen Pagen, Laquayen und Lauffern aber die Aufwartung hatten. Alle Leute von Distinction hatten Erlaubniß in die Zelte zu gehen, und die hohe Gesellschafft speisen zu sehen, die gemeine Leute aber konnten solches von außen über die Schantze weg betrachten. 95

Aber nicht nur die Janitscharenmusiker, ihre ungewöhnlichen und besonders aufwendig gestalteten Instrumente ${ }^{96}$ und ihre exotisch klingende Musik trugen zur besonderen zeremoniellen Wirkung bei, sondern auch die eigentlich in Europa längst eingebürgerten und vertrauten Pauken konnten Furore machen. Bei der General=Revue am 1. Juni 1730, die von beiden Majestäten mit riesigem Gefolge abgenommen wurde, traten auch Musiker in Aktion. In der Beschreibung heißt es dann: [...] und ist nicht zu vergessen, daß unter allen Musicalischen Kriegs=

94 Das Sächsische Feld=Lager (wie Anm. 47), S. 22 f. (Hervorhebung original). Vgl. hierzu den „Plan mit den Zelten und Pavillons bei Beendigung des Manövers bei Zeithain, 1730" (http://www.digam.net/?dok=6150; Signatur: HStAM Karten WHK 38/110; Zugriff am 10. September 2012), der veranschaulicht, dass die Trompeter und Pauker auf der einen Seite, die Janitscharenmusiker auf der anderen Seite den zentralen Exerzierplatz flankierten und damit optisch eine herausragende Stellung einnahmen. Die Wirkung der Janitscharen und ihrer Musik wurde noch verstärkt durch zahlreiche prächtige türkische Zelte, die man für die Königlichen Hoheiten aufgestellt hatte. Das Sächsische Feld=Lager (wie Anm. 47), S. 4 (Hervorhebung original).

In einer anderen Beschreibung des Campements heißt es, die Trommeln seien sebr groß und schön gemacht; Ausführliches und richtiges Journal (wie Anm. 85), S. 23. Im Übrigen gab der Verfasser das Gerücht wider, der König habe extra nach Konstantinopel geschickt, um die Trachten der Janitscharen, wie sie in der Türckey würcklich gehen, zu erbalten. 
Instrumenten, welche während der Parade sich tapfer hören liessen, die extra ordinaire grosse und propre Artillerie=Paucken, die mitten vor dem Parc der Artillerie auf einem Wagen stunden, und wie eine Glocke klungen, auch von dem entsetzlichen grossen Finnländer (in Türckische Tracht gekleidet), geschlagen wurden, zu admiriren. 97

Für diesen ,großen Paukenwagen' interessierte sich der preußische König lebhaft. Es handelte sich um ein technisches Wunderwerk, das kurz zuvor von einem Mann namens Gottfried Schmidt aus Lauban erfunden worden sein soll. Der Wagen bestand aus zebn also in einer erhabenen Stellage rangirten Paucken [...], dass sie alle zehn von einer Person geschlagen werden konnten.98

Zwei Schlagwörter des oben stehenden Zitats kennzeichnen nicht nur eine besondere musikalische Invention, sondern den Sinn und die Zielsetzung des Campements insgesamt und die Bedeutung, welche der Visualisierung von musikalischen Aktionen zukam, treffend: extra ordinaire gross und propre. Erstere Begriffe sprechen für sich - wobei die Figur des als Türke verkleideten Finnen die Wirkung noch deutlich steigerte -, das zweite Epitheton erklärt sich aus dem Kontext des Berichts. Alles, was ins Auge sprang, was als schön, prächtig und eindrucksvoll empfunden wurde, erhielt das Attribut ,propre'. So formulierte der Autor der anonym erschienenen Beschreibung des Campements als Fazit seines Berichts: Das Vergnügen, so Ibro Königl. Majest. in Preussen über diese schöne und propre Armée hatten, war nicht auszusprechen, und die Menge der Fremden unzeblbar. ${ }^{99}$

Der Blick auf die Situation in Weimar und Dresden zeigt zwar, dass die Herrscher sehr unterschiedlich mit der Janitscharenmusik umgingen und man sich daher vor Verallgemeinerungen hüten muss. Eines aber steht fest: Für repräsentative Zwecke wurde diese Musik ab 1700 an allen Höfen nahezu unverzichtbar und gezielt eingesetzt. ${ }^{100}$ Sie trat den bis dahin üblichen musikalischen Herrschaftssymbolen gleichberechtigt an die Seite und vermochte sie wirkungsvoll zu verstärken. Dass bei den Janitscharen das äußere Gesamtbild - Instrumente, Montur, gegebenenfalls Hautfarbe, Körpergröße - in ähnlicher Weise zur repraesentatio beitrug, wie das für die Trompeter und Pauker vielfach belegt ist, lässt sich nicht bestreiten. ${ }^{101}$

\footnotetext{
97 Das Sächsische Feld=Lager (wie Anm. 47), S. 5 (Hervorhebung original).

98 BesCHORner, Zeithainer Lager (wie Anm. 91), S. 75.

99 Das Sächsische Feld=Lager (wie Anm. 47), S. 8 (Hervorhebung original).

100 Ein Beleg aus Gotha bestätigt die besondere Bedeutung der Janitscharenmusik für repräsentative Musikaufführungen. Am 23. Januar 1807 attestierte der Concertmeister Louis Spohr die Abrechnung für die Mitwirkung von sechs Regiments-Hautboisten bei Probe und Aufführung einer vom damaligen sachsen-gothaischen Erbprinzen Friedrich (1774-1825; reg. seit 1822 als Friedrich IV.) komponierten Arie mit Janitschar Musick; Thüringisches Staatsarchiv Gotha, Friedensteinsche Kammerrechnungen - Belege 1806/07, Beleg Nr. 2415/16.

101 Die Betonung des äußeren Erscheinungsbildes durch aufwendige, exotisch anmutende Monturen oder besonders kunstvoll gearbeitete Instrumente war allerdings auch bei anderen höfischen Musikformationen üblich, etwa bei den sogenannten Bockpfeifern
} 


\section{Besondere Anlässe}

\section{Schlittenfahrten}

Solenne Schlittenfahrten hatte bereits Bernhard von Rohr 1733 in seiner Ceremoniel-Wissenschafft ${ }^{102}$ explizit unter den herrschaftlichen Divertissements aufgeführt. ${ }^{103}$ Dass derartige Fahrten in Weimar willkommene Anlässe boten, Macht und Bedeutung der Herzöge zu demonstrieren, lässt sich verschiedenen Quellen entnehmen. ${ }^{104}$

Anfang 1760 findet sich im Fourierbuch die Angabe, dass die Prinzessin Ernestine [Auguste Sophie; 1740-1786; seit 1758 Herzogin von Sachsen-Hildburghausen] eine Schlittenfahrt unternommen habe, bei der die Hautboisten-Bande auf einem besonderen Schlitten vorangefahren sei. ${ }^{105}$

Eine Nachricht unter dem Datum des 18. Januar 1760 besagt: Nach geendigter Tafel bielten Durchl. Herzogin eine Solenne Schlittenfarth [sic!] mit Trompetten und Paucken auch Janitscharen Musique und fubren in der Stadt, und nach Belvedere alda wurde Bischet [Biscuit?] Caffee Thee und Confitteur [sic!] herum gegeben. ${ }^{106}$ Diese Beschreibung beweist, dass die Janitscharenmusik gemeinsam mit Trompeten und Pauken eine emblematische Funktion erfüllte und im Hinblick auf die zeremonielle Bedeutung mit diesen annähernd auf gleicher Stufe stand.

Es kann nicht verwundern, dass die Ausstattung von Schlittenfahrten ebenfalls einem strikten zeremoniellen Reglement unterworfen war. Neben gleichsam ,privaten'Fahrten vom Schloss in die nähere Umgebung oder zum Lustschloss Belve-

(Dudelsackbläsern); vgl. Samantha Owens, „Gedancken für ein gantzes Leben“. Polnischer Bock music at the Württemberg court c 1730, in: The Consort. European Journal of Early Music 54 (1998), S. 43-56, hier S. 51 f.; sowie Accurate Beschreibung (wie Anm. 62), S. 23. Es hat den Anschein, als habe man bei den Janitscharen wie den Bockmusikern bestimmte musikalische Defizite, genauer: vom Instrumentarium bedingte Einschränkungen, durch den äußeren - „propren“ - Eindruck der Musiker und ihrer Instrumente kompensieren wollen.

102 Siehe oben Anm. 11.

103 Vgl. die Beschreibung der Solennen kaiserlichen Schlittenfahrten in Wien im Dezember 1666/Januar 1667 sowie am 22. Januar 1716; LüNING, Theatrum Ceremoniale Politicum (wie Anm. 30), Bd. 2, S. 1189 f. und S. 1207 f.

104 Gleiches gilt für den kurfürstlichen Hof zu Dresden, wo nicht nur Hautboisten sowie Trompeter und Pauker eingesetzt wurden, sondern bei Bedarf auch Stadtpfeifer; vgl. hierzu Hermann Techritz, Sächsische Stadtpfeifer. Zur Geschichte des Stadtmusikwesens im ehemaligen Königreich Sachsen, Dresden 1932, S. 4, Anm. 9. Eine interessante Beschreibung des Aufwandes, der bei Schlittenfahrten in Weimar zur Zeit Anna Amalias getrieben wurde, liefert Karl Freiherr von Lyncker: Am Weimarischen Hofe unter Amalien und Karl August. Erinnerungen von Karl Frhr. von Lyncker, hrsg. von Marie Scheller, Berlin 1912, S. 29 f.

105 HStA Weimar, Hofmarschallamt Nr. 4502, Fourierbuch 10. November 1749 bis 28. Dezember 1753, S. 50, Datum: 8. Januar 1750.

106 HStA Weimar, Hofmarschallamt Nr. 4508, Fourierbuch 1. Mai 1759 bis 20. April 1760, fol. 118v (S. 236), Datum: 18. Januar 1760. 
dere, die ohne großen Aufwand durchgeführt wurden, standen andere, deren festlicher und zeremonieller Charakter in der Zahl der Schlitten, der Größe der Entourage, aber auch in der Wahl der Fahrtroute zum Ausdruck kam, und nicht zuletzt darin, dass diese Ausfahrten nachmittags um vier Uhr stattfanden. ${ }^{107}$ Man bediente sich einer genau berechneten, Choreographie‘, deren vornehmstes Ziel es war, möglichst vielen Untertanen die Möglichkeit zu eröffnen, das Spektakel zu bewundern. ${ }^{108}$

Mit vergleichsweise geringem äußeren Pomp unternahm die damals 10jährige Prinzessin Ernestine Anfang Januar 1750 eine Schlittenfahrt, über die es im Fourierbuch hieß: Voraus fubr auf einem Schlitten die Hautboisten-Bande. ${ }^{109}$ Größer war das Gefolge, wenn der Herzog oder die Herzogin selbst bzw. der Prinzregent ausfuhren, obschon beispielsweise Carl August (1757-1828) gelegentlich weniger Aufwand als sonst üblich betrieb. Von einer Schlittenfahrt im Januar 1778 berichtet das Fourierbuch, dass der Prinz nach Belvedere fuhr und anschließend nach Weimar zur Herzogin Mutter zurückkehrte, alwo Concert gehalten wurde. Beÿ der Schlittenfabrt waren die Regiments Hautboisten mit ibrer Music zugegen und mußten bintendrein fabren. ${ }^{110}$ Zeremoniell aufwendiger war eine Ausfahrt im Winter 1774. Dem Zug voran fuhr ein vierspänniger Schlitten mit Trompeten und Pauken, Den Beschluß machte ein Vier spänniger Schlitten mit der Jannicharen [Janitscharen] Music und einige Hußaren. ${ }^{111}$ Gelegentlich konnten überdies weitere Insignien das Zeremoniell verstärken: Heute nachmittag um 4. ubr war eine [Solenne] Schlittenfabrt gebalten, 2. Postillions [sic!] ein Commando Hussaren gingen voran alsdan ein Schlitten mit der Janitscharen Music und so folgete der Zug nach; im Redouten Hauße stiegen die Herrschafften aus und war alda Ball gebalten auch abends alda gespeißet. ${ }^{112}$

Die Verbindungen dieser akustischen und optischen Elemente - Posthörner trugen in Weimar Verzierungen ähnlich denen von Trompeten; der Schlitten hatte vier Pferde, nicht lediglich zwei wie sonst üblich - sowie gestischer Zeichen - die Postillons bliesen, wie zeitgenössische Bildquellen belegen, ihre Hörner in einer charakteristischen Haltung - zum Zwecke der repraesentatio sind ganz sicher im

107 Siehe die Belege unten.

108 Vgl. hierzu auch die Schilderung von Paul KüHn, Weimar, hrsg. von Hans Wahl, Leipzig 21919, S. 27 f.

109 HStA Weimar, Hofmarschallamt Nr. 4502, Fourierbuch 10. November 1749 bis 28. Dezember 1753, S. 50, Datum: 8. Janauar 1750.

110 HStA Weimar, Hofmarschallamt Nr. 4527, Fourierbuch 1. Januar bis 31. Dezember 1778, fol. 5 (S. 6), Eintrag vom 6. Januar 1778.

111 HStA Weimar, Hofmarschallamt Nr. 4523, Fourierbuch 1. Januar bis 31. Dezember 1774, fol. 324 (S. 326), Datum: 30. November 1774. Dazu hat der Fourier folgende Anmerkung gesetzt: Trompeter u. Paucker bekabmen jeder 1. Maas [0,89 Liter] Wein.

112 HStA Weimar, Hofmarschallamt Nr. 4531, Fourierbuch 4. Januar bis 31. Dezember 1782, fol. 249 (S. 259). Der Eintrag datiert vom 29. November 1782. 
Sinne von Henze-Döhrings „synästhetischer Verknüpfung“113 zu interpretieren, obschon die Verfasserin diese spezielle Form der Machtdarstellung offenkundig nicht in Betracht gezogen hatte, sie jedenfalls nicht eigens erwähnte. An dem hier zitierten Beispiel lässt sich erkennen, dass prinzipiell beinahe alle Objekte, alle Stände, alle Handlungen, alle Anlässe sich zur Majestätsverherrlichung einsetzen ließen und dass sich dies nicht auf jene vergleichsweise wenigen Aktivitäten beschränkte, die heutzutage von der Forschung besonders in den Blick genommen werden.

War die Ausfahrt nicht privater, sondern offizieller - sozusagen staatsmännischer [bzw. staatsfraulicher] - Natur, dann wurden die Schlittenfahrten mit dem Epitheton „Solennel“ [feierlich] versehen; etwa ein Aufzug der verwitweten Herzogin Anna Amalia (1739-1807; 1758-1775 Vormundschaftsregentin für den unmündigen Sohn Carl August) Anfang 1760: Nach geendigter Tafel hielten Durchl. Herzogin eine Solenne Schlittenfarth [sic!] mit Trompetten und Paucken auch Janitscharen Musique und fubren in der Stadt, und nach Belvedere alda wurde Biscuit Caffee Thee und Confitteur herum gegeben.114

Es ist bemerkenswert, dass die Janitscharen, die bei anderen Ausfahrten ${ }^{115}$ gemeinsam mit den Hautboisten aufgetreten waren, hier mit den Trompetern und Paukern zusammen musizierten. Der Umstand belegt, dass unter dem Gesichtspunkt der repräsentativen Funktion keine Unterschiede zwischen diesen beiden Formationen bestanden. Wichtig war für die Zeitgenossen, dass sie entscheidend zur Steigerung der repräsentativen Wirkung beitragen konnten. ${ }^{116}$ Bezeichnend für die zeremoniell-repräsentative Bedeutung der Weimarer Schlittenfahrten ist überdies, dass die Herzogin mit ihrem Gefolge nicht auf direktem Wege nach Belvedere fuhr, sondern einen Abstecher in die Stadt machte, um sich bei einer Rundfahrt ([Durchl. Herzogin] fubren in der Stadt [Hervorhebung d. V.]) einer möglichst großen Volksmenge zu präsentieren und deren Huldigung entgegenzunehmen. ${ }^{117}$

Mehr Pracht entfaltete Herzog Carl August bei einer solennen Schlittenfahrt, zu der der gesamte Hofstaat geladen war. Wieder wurde der Weg durch die Stadt gewählt, diesmal aber sowohl auf dem Hin- als auch auf dem Rückweg. Dass letzterer am Abend durch den Glanz von Fackeln illuminiert wurde, verlieh ihm ein zusätzliches Pracht-Element, wenngleich, wie der Fourier anmerkt, zwar zwei Husaren-Abteilungen mitfuhren bzw. -ritten, auf Musik jedoch (aus unbekanntem Grund) verzichtet wurde: Heute Mittag um 4. Ubr hielten Durchl. Herzog

113 Henze-Döhring, Musik im höfischen Zeremoniell (wie Anm. 4), S. 24.

114 HStA Weimar, Hofmarschallamt Nr. 4508, Fourierbuch 1. Mai 1759 bis 20. April 1760, fol. 118 (S. 236), 18. Januar 1760.

115 Siehe oben den Beleg von 1778.

116 Vgl. auch den oben zitierten Bericht von 1774.

117 Das Fahren durch die Residenzstadt, wobei an verschiedenen Stellen Soldaten und Trompeter postiert waren, schildert auch von Rohr als ein für dieses Divertissement bedeutsames Zeremoniell; RoHr, Ceremoniel-Wissenschafft (wie Anm. 11), 4. Teil, Kap. IX: Von Schlittenfahrten, S. 834-383, hier S. 834. 
eine Solene [sic!] Schlittenfahrt, es waren sämtl. Cav[aliers] und Dames auch Fräul. darzu invitiret. Bë̈ dem Fürsten Hauße stiegen die Herrschafften ein fubren ein paar mabl herum und als dan nacher Beveldere alwo die Herrschafften warme Geträncke zu sich nabmen. Abends kabmen Sie sämtl. unter Flambos von Bellvedere [sic!] wieder herein, fubren wiederum etl. Mabl in der Stadt berum und stiegen beÿ den Hr. Graf von Rether aus alwo Assemblée gehalten wurde. 2 Hussaren Commando waren dabeÿ aber keine Music. ${ }^{118}$

Nochmals prächtiger ausgestattet mit unterschiedlichsten Insignien der Macht war eine Schlittenfahrt im Dezember 1782. Das Fourierbuch berichtet darüber folgendes: Heute nachmittag um 4. uhr war wieder eine Sollene [sic!] Schlittenfabrt gebalten; solche bestand aus 22. Schlitten, ein Commando Hussaren ging voran. 3. Postillions desgl.; alsdan kam ein Schlitten mit der Janitscharen Music, dan der Oberbereiter von Durchl. Herzog, und so ging der Zug weiter, es war ins Belvedere gefabren und oben Thee und Kliender [Fliender = Flieder?] Wein getrunken; als dan wieder herunter etl. mabl in der Stadt herum gefabren und beÿm Redouten Hauße stiegen die Herrschafften aus und war Ball gebalten auch alda gespeißet. ${ }^{119}$

2. Musizieren vor und während der Tafel sowie Gesundheit-Trinken Nach Claudia Curtius Seutter von Lötzen ${ }^{120}$ war das Gesundheit-Trinken an herrschaftlichen Tafeln unter musikalischer und akustischer Signalgebung durch Trompeten und Pauken einerseits, Böller- und Kanonenschüsse andererseits, nur an einigen Höfen üblich.121 Wie nachfolgend gezeigt werden soll, hatte es in Weimar und Dresden eine große Bedeutung und folgte akribisch festgelegten Regeln. ${ }^{122}$ (Dass es gelegentlich sogar von der Bevölkerung, zumindest von deren

118 HStA Weimar, Hofmarschallamt Nr. 4533, Fourierbuch 1. Januar bis 31. Dezember 1784, fol. 17 (S. 13), Datum: 12. Januar 1784.

119 HStA Weimar, Hofmarschallamt Nr. 4531, Fourierbuch 4. Januar bis 31. Dezember 1782, fol. 254 (S. 256), Eintrag vom 4. Dezember 1782.

120 Curtius Seutter von Lötzen, Tafelzeremoniell (wie Anm. 21), S. 126. In Wien soll es 1788 abgeschafft worden sein; ebd., S. 131.

121 Auf welche Quellen sich die Verfasserin bei ihrer Aussage stützt, ist nicht ganz klar. RoHr, Ceremoniel-Wissenschafft (wie Anm. 11), Kap. VIII: Von dem Tafel=Ceremoniel, S. 90-132, hier S. 117, charakterisiert das Gesundheit-Trinken unter Trompeten- und Paukenschall und sogar Kanonenschüssen keineswegs als eine umstrittene Besonderheit. Die Wichtigkeit von Schüssen und Feuerwerk hebt WolfF, Vernünfftige Gedancken (wie Anm. 3), \$391, S. 387, ausdrücklich hervor: Es verdienet hier auch seine Stelle das Freuden=Schiessen so wobl mit groben, als kleinem Geschütze, nebst allen Fener= Wercken, die einen Knall von sich geben, wenn sie zerspringen, gleichwie sie an sich auch dem Auge Vergnügen machen [...]. Und Friedrich Carl von Moser (Teutsches Hof= Recht, Bd. 2, Frankfurt/Leipzig 1755, S. 547) schreibt ausdrücklich, das GesundheitTrinken sei ein Stück des Ceremoniels bey allen und zumablen grossen Tafeln.

122 Welche Bedeutung das Gesundheit-Trinken am preußischen Hof hatte, geht aus den Beschreibungen der Zeremonien bei der Krönung Friedrichs I. zum König in Preußen am 18. Januar 1701 hervor; vgl. LüNING, Theatrum Ceremoniale Politicum (wie Anm. 30), Bd. 2, S. 92-121, hier insbesondere S. 108. 
ständischen Vertretern, als Mittel der Huldigung eingesetzt werden konnte, wurde oben bereits gezeigt.) Ein wichtiger Beleg für die Bedeutung des Tafelzeremoniells ist nicht zuletzt das Campement von 1730. Im Artikel des Zedler-Lexikons heißt es dazu: Die Music aber blieb vorgedachter massen auf beyden Seiten steben, und wenn getruncken wurde, so erschalleten alle Instrumente auf einmabl, die Canons aber wurden beständig mit unter gefeuert. Was vor ein prächtiges Anseben es gegeben, so viel Trompeten und Paucken, ja so viel Wald=Hörner und übrige musicalische Instrumente der gantzen Armee mit untermischten unaufhörlichen Krachen so vieler Canons, auf einem Platz zu bören, kan sich ein jeder leicht vorstellig machen. ${ }^{123}$

Es wäre irrig anzunehmen, dass sich die Verbindung dieser Repräsentationsmittel allein aus der Tatsache erkläre, dass die Veranstaltung im Freien ablief. Das trifft lediglich auf die Kanonenschüsse zu. Im Übrigen bediente man sich auch innerhalb der Schlossgebäude verschiedenster musikalischer Repräsentationsformen, die je nach Bedeutung der Tafel hierarchisch abgestuft waren. ${ }^{124}$ Insgesamt lassen sich folgende Besetzungs- bzw. Veranstaltungstypen feststellen:

- 1. Stufe: 1 Trompeter bläst [so 1749 beim Geburtstag der Prinzessin Johanna Charlotte ${ }^{125}$ (1693-1751), jüngste Tochter von Herzog Johann Ernst III. (1664-1707)] bzw. 1 Pauker schlägt ${ }^{126}$

- 2. Stufe: Trompeter und 1 Pauker blasen und schlagen

- 3. Stufe: Trompeter und 2 Pauker ${ }^{127}$ blasen und schlagen

- 4. Stufe: zusätzlich wird eine Tafelmusik aufgeführt, und zwar von den Hautboisten und/oder der Hofkapelle

- 5. Stufe: zusätzlich wird vor und/oder nach der Tafel Ball gehalten, bei dem, zur nochmaligen Steigerung der Exklusivität, Trompeter und Pauker mitwirken

123 Artikel: Mühlberg (wie Anm. 84), Sp. 114 f.

124 Zum Tafelzeremoniell am Dresdner Hof vgl. Henze-DöHring, Musik im höfischen Zeremoniell (wie Anm. 4), S. 28 f. Angesichts des strikten Reglements, dem grundsätzlich alle musikalischen Aktivitäten vor und bei einer Tafel unterworfen waren, erscheint Henze-Döhrings These, die Tafelmusik habe „allein unterhaltenden Charakter" gehabt, „Zeichenhaftigkeit“ sei ihr allenfalls insofern zugekommen, „als die Qualität der Darbietung Rückschluß auf den materiellen Reichtum und den allgemein kulturellen Rang der Residenz zuließ“ (ebd., S. 30), wenig überzeugend.

125 HStA Weimar, Hofmarschallamt Nr. 4501, Fourierbuch 10. November 1749 bis 28. Dezember 1753, fol. 15v (S. 18), Datum: 23. November 1749. Beim Kaffeetrinken nach der Mittagstafel wurde eine Music mit Trompeten und Paucken gemacht; zur Abendtafel blies ein Trompeter.

126 HStA Weimar, Hofmarschallamt Nr. 4503, Fourierbuch 10. November 1749 bis 28. Dezember 1755, fol. 154 (S. 156). Am 27. Mai 1755 wurde Landtag gehalten; im Fourierbuch heißt es dazu: beute Mittags halb 1: Ubr wurde zur Tafel geschlagen /:zu andererzeit wenn nicht Galla Tag beÿ Hofe war, bließ nur ein Trompeter:\.

127 HStA Weimar, Hofmarschallamt Nr. 4511, Fourierbuch 7. März bis 11. Mai 1757, fol. 36v (S. 73), 28. April 1757. Beim Besuch des Gothaer Herzogspaares und des Erbprinzen in Eisenach wurde mit 2 Paar Paucken 2 mabl zur Tafel und zum dritten mabl ausgeschlagen. 
konnten. 128 [Diesen Abend war vor und nach Tafel Ball gebalten, und zur Tafel wie Mittags, mit Trompeten und zweÿ Paar Paucken geschlagen und gebla$\left.\operatorname{sen}^{129}\right]$

Interessant in unserem Zusammenhang sind Erläuterungen zur musikalischen Gestaltung von Tafelzeremonien, die die Weimarer Hofverwaltung 1749 zusammenstellte. Man orientierte sich dabei, wie übrigens auch hinsichtlich der Rangordnung bei Hofe, am Zeremoniell der Herzöge von Sachsen-Gotha. ${ }^{130}$ In der Auflistung werden die zeremoniellen Akte zum Geburtstag des jeweils regierenden Herzogs folgendermaßen beschrieben:

Actum [Zeremoniell zum Geburtstag des Herzogs von Sachsen-Gotha; 25. April]

Serenissimi Domini Tutoris Gothani;

1. Mittags Tafel 24 Personen

[es folgen Einzelheiten der Speisen, des Geschirrs etc.]

3. Wird wie bë̈ Galla und Geburths Tägen bräuchlich, zur Tafel geschlagen

4. Bë̈m Gesundheit Trincken geben Trompeten und Paucken, auch wird wäbrender Tafel, durch die Hautboisten, Tafel Music gemachet

5. Nach Tafel wird [Karten] gespielt und Ball gehalten

[...]

7. Wird Mittags in den großen Zimmer über den Churfürstl. Zimmern Tafel gehalten da denn die Music auch Trompeten und Paucken auf die Gallerie placiret werden können

8. Sonntags darauf geschiehet die Abkündigung dieses Hochfl. Geburths Tages in der SchloßKirche, und nach der Predigt, wird unter Trompeten und Paucken das Te Deum Laudamus abgesungen. ${ }^{131}$

Über die Zeremonien anlässlich des „Beilagers“ (Hochzeit) der Weimarer Prinzessin Ernestine Albertine (1722-1769) und des Grafen Philipp II. Ernst zu Schulenburg-Lippe (1723-1787) am 6. Mai 1756 berichtete der Hoffourier: [...] nach

${ }^{128} \mathrm{Da}$ damals lediglich Naturtrompeten verfügbar waren und sich nicht der geringste Hinweis darauf findet, dass die Hoftrompeter in der Lage waren, Clarinpartien zu blasen, kann ihre Mitwirkung lediglich in der Ausführung von Signalen, Tuschs und Fanfaren bestanden haben.

129 HStA Weimar, Hofmarschallamt Nr. 4505, Fourierbuch 11. September 1757 bis 30. Juni 1758, fol. 51r (S. 54). Am Abend war bei Hofe Assemblée. Im Artikel „Assemblée“ des Zedler-Lexikons, Bd. 2 (1732), Sp. 1902, heißt es: Assemblée, die Versammlung oder Zusammenkunft, welche bey grosser Herrn=Höfen, oder vornehmen Ministern geschiehet, und sich die Cavalliers und Damen in Spielen, Tanzen und anderen Lustbarkeiten divertiren.

130 Erbprinz Ernst August II. Constantin (1737-1758) war beim Tod seines Vaters Ernst August I. (1688-1748) erst elf Jahre alt und stand daher zunächst unter der Vormundschaft des Herzogs Friedrich III. (1699-1772; reg. 1732-1772) von SachsenGotha.

131 HStA Weimar, Kunst und Wissenschaft - Hofwesen A 9186, Hofmarschall Ambts= Acta Die Solennisirung derer HochFürstl. Geburths Täge betr. A.[anno] 1748 [ergänzt: 1745, 1749], fol. 7r/v, Datum: 23. April 1749. 
d. Vermählung ward zur Tafel mit Trompeten und Pauken geschlagen u. geblasen, und Durchl. Herzog führten Princessin Braut zur Tafel. Es waren 3 Tafeln, 1 Fürstl. und 2. Marchalls Tafeln, die Fürstl. Tafel wardt doppelt servirt, unter wäbrend. Tafel wardt Musique, und der Gesundheit wardt unter Trompeten u. Paukenschall getrunken, nach der Tafel war Ball mit Trompeten und Pauken welche Durchl. Herzog mit Princessin Braut eröffneten [...]. ${ }^{132}$

Für den 13. Geburtstag des Weimarer Erbprinzen am 2. Juni 1750 bestimmte das Zeremoniell folgenden Ablauf:

5. Umb 12 Ubr wird das erstemabl zur Tafel geschlagen, halb 1. Uhr das 2te. und umb 1. Ubr das 3te. Mabl ausgeschlagen, und geblasen, und zwar auf den Balcon übern Aufritte.

6. Wäbrend den Gesundheit Trincken gehen Trompeten und Paucken, auch wird unter der Tafel, Music anfgefübret. [...]

10. Sodann wird umb $7 \mathrm{Ubr}$ das 1 ste umb halb $8 \mathrm{Ubr}$ das 2 te. und umb $8 \mathrm{Ubr}$ das 3te mabl zur Tafel geschlagen, und geblaßen [...]

11. [...] wäbrender Tafel wird Music anfgefübret

[Abends dann Ball gehalten].133

Die leider sehr raren Informationen über die Zahl der mitwirkenden Musiker zeigen, dass zumindest bei den Geburtstagen des regierenden Weimarer Herzogs während des Tafelzeremoniells ein erhebliches Lautstärke-Potenzial entfaltet wurde. So spielten bei der Feier zum 19. Geburtstag Herzog Ernst August II. Constantins von Sachsen-Weimar am 2. Juni 1756 nicht weniger als neun Trompeter und ein Pauker. ${ }^{134}$

Dass auch am Dresdner Hof das Gesundheit-Trinken eine außergewöhnliche Bedeutung hatte, geht aus der Beschreibung des Campements von 1730 hervor. Am Ende des letzten Tages ritt der preußische König die Linien und die OffiziersTafeln ab, machte den Offizieren für die Präsentationen ihrer Soldaten Komplimente, wofür die Offiziere sich mit dem Gesundheit-Trinken revanchierten: Ibro Königl. Majest. in Preussen beliebten in der Retour an alle Officiers-Tafeln zu reiten, und sämtl. Officiers Ibr allergn[ädigstes] Compliment zu machen, welche auch allezeit Ihro Majest. allerhöchste Gesundheit, zugleich unter Trompeten Touch, truncken. ${ }^{135}$ Und an anderer Stelle der Beschreibung heißt es, dass zum

132 HStA Weimar, Hofmarschallamt Nr. 4504, Fourierbuch 24. März bis 28. Oktober 1756, fol. 22r (S. 45).

133 HStA Weimar, Kunst und Wissenschaft - Hofwesen A 9186, fol. 15r-16v, hier fol. $16 \mathrm{r} / \mathrm{v}$.

134 HStA Weimar, Hofmarschallamt Nr. 4504, Fourierbuch 24. März bis 28. Oktober 1756, fol. 38r (S. 75); hier heißt es: Beÿ der [Mittags-] Tafel war Concert und wurde die Gesundheit unter Trompeten u. Pauken Schall getrunken [...]. Fol. 39v (S. 78) sind neun Trompeter und ein Pauker als Mitwirkende erwähnt. Beim Einzug des jung vermählten Erbprinzen mit seiner Gemahlin in Dresden 1719 bliesen und schlugen nach den Gottesdiensten in den beiden Hofkirchen nicht weniger als 36 Trompeter und 3 Pauker zur Tafel; Accurate Beschreibung (wie Anm. 62), S. 15.

135 Das Sächsische Feld=Lager (wie Anm. 47), S. 22 (Hervorhebung original). 
Gesundheit-Trinken Kanonenschüsse abgefeuert wurden: Vor den Königl. Zeltern stunden auf beyden Flügeln alle Paucken von der gantzen Armee, und hinter selbigen 24. Canonen, die bey dem Gesundheit=Trincken loßgebrennet wurden. ${ }^{136}$

Bei der Hof-Tafel in Weimar konnten durchaus andere als die üblichen Musiker aufwarten; auch sie vermochten den zeremoniellen Anforderungen zu entsprechen. So heißt es in den Weimarer Schatullrechnungen unter dem Datum des 9. August 1731, es seien fünf Thlr. gezahlt worden. Auf Gnädigsten Befebl den Spielleuden so beÿ Taffel aufgewartet. ${ }^{137}$ Und mindestens bis in die 1750er-Jahre hinein existierte eine Gruppe von Bockpfeifern (Dudelsackspielern), die ebenfalls zu Repräsentationszwecken eingesetzt wurden. Ein Eintrag in den Schatullrechnungen vom April 1734 besagt, dass von den 744 Thlr. Trinkgeld, welche die Fürstl. Brandenburg Bareütischen [sic!] Herrschaften für jene Bediensteten des Weimarer Hofstaats austeilten, die sie während des Aufenthaltes betreut hatten, neben den Trompetern und Paukern (zusammen 20 Thlr.) und der Hofkapelle (ebenfalls 20 Thlr.) auch die Mitglieder der Bock Musique (15 Thlr.) bedacht wurden. ${ }^{138}$ Angesichts der Tatsache, dass das Trompetercorps damals fünf Mitglieder umfasste und die Hofkapelle elf, war das Trinkgeld für die drei Bockmusiker überproportional hoch - ein indirekter Beleg für deren, Wertigkeit' im Rahmen der repraesentatio majestatis.

\section{Auf der Suche nach dem Außergewöhnlichen}

Das Bestreben, die Adressaten des Zeremoniells durch außergewöhnliche Ereignisse und singuläre Darbietungen zu beeindrucken, zieht sich wie ein roter Faden durch die Geschichte der repraesentatio majestatis. Ungewöhnliche oder unbekannte Instrumente waren dazu augenscheinlich hervorragend geeignet. Nur so ist es zu erklären, dass viele Höfe begierig neu erfundene Instrumentenmodelle anschafften, die zwar kurzfristig für Aufsehen sorgten und buchstäblich aufhorchen ließen, von denen die meisten sich allerdings letzten Endes in der Praxis nicht

136 Ebd., S. 22.

137 HStA Weimar, Fürstenhaus A 871, Schatullrechnungen Ernst August I. vom 1. November 1730 bis 1. Januar 1733, Datum: 9. August 1731.

138 HStA Weimar, Fürstenhaus A 873, Schatullrechnungen Ernst August I. Januar bis Dezember 1734, fol. 200 (ohne Datum). Zur Bockmusik kamen in Weimar, soweit erforderlich, noch drei sogenannte Bergsänger. Bockpfeifer, Bergsänger und andere, teilweise in höfischen Diensten stehende Spieler volksmusikalischer Instrumente oder entsprechende Sänger wurden u. a. bei den sogenannten Bauer=Hochzeiten (vgl. RoHR, Ceremoniel-Wissenschafft (wie Anm. 11), Kap. VIII: Von den Wirthschafften und Bauer=Hochzeiten, S. 824-833) oder einer andern Verkleidung sowie bei Tafeln in Jagt= und Forst=Häusern eingesetzt, damit alles zusammen harmoniren möge (ebd., S. 120). Auch beim Zeithainer Campement 1730 kamen Bockpfeifer zum Einsatz; Ausführliches und richtiges Journal (wie Anm. 85), S. 30. Zur repräsentativen Funktion von Bockpfeifern an deutschen Fürstenhöfen vgl. Owens, Polnischer Bock music (wie Anm. 101), S. $51 \mathrm{f}$. 
zu behaupten vermochten. Lediglich für eine kurze Zeit erfüllten sie ihren Zweck als ,Exemplum ‘ für das Außergewöhnliche und den spezifischen Repräsentationsanspruch des betreffenden Herrschers und verstaubten dann in abgelegenen Kammern des betreffenden Schlosses. 139

Die Parade der Truppen während des Campements von 1730, die mehr als fünf Stunden dauerte und bei der die Vorbeiziehenden eine strikt hierarchische Ordnung einhielten, ${ }^{140}$ wurde angeführt von Ibro Königl. Hoh. De[m] Polnische[n] Printz zu Pferde. An siebenter Stelle paradierte die Esquadr. Grenadiers à Cheval, die ihrerseits als visuelles und akustisches Prunkstück unter den Hautboisten 2 meßingne Halb=Trompeten [mitfübrte], welche dermassen schrien, daß man sie vor Trompeten und Pauken hören konnte. Hier wurde de facto eine Entwicklung vorweggenommen, die die Freiluftmusik in Frankreich nach der Revolution von 1789 entscheidend prägte: die Einführung von Blechblasinstrumenten - unter ihnen insbesondere die antiken Vorbildern nachempfundene tuba curva - mit außerordentlich beschränktem Tonvorrat, deren einziger, Vorzug' in der ungewöhnlichen Form und einer besonders großen Lautstärke lag. ${ }^{141}$ Und es ist bezeichnend, dass diese Maxime gleichermaßen das Repräsentationsbedürfnis einer Monarchie wie das einer Bürgerdemokratie bestimmen konnte.

Die Aktivitäten während des Campements von 1730 vermitteln konkretere Informationen über Zielsetzungen und aufgebotene Mittel der repraesentatio majestatis als viele theoretische Quellen. Rohr etwa gibt in den aufgelisteten Veranstaltungsarten weder Informationen darüber, wer an ihrer Ausführung beteiligt war, noch darüber, wie und wo sie eingesetzt wurden. Vor allem aber lässt sich aus heutiger Sicht und aufgrund der mangelnden Erfahrung nicht nachvollziehen, wie sie miteinander kombiniert und in ihrer Wirkung gesteigert wurden. Denn selbst einem so standesbewussten Herrscher wie August dem Starken fehlten die finanziellen Mittel, um auf jeder einzelnen Ebene das Optimum an Außenwirkung zu erreichen, das er angesichts seines Ranges für notwendig erachtete, und das dafür notwendige Personal ständig vorzuhalten. Insofern war er, wie weniger bedeutende Potentaten auch, darauf angewiesen, eine möglichst effektvolle Verbindung verschiedenster Mittel zu realisieren. Der besondere Wert des Campements von 1730 für die Beschäftigung mit Techniken der Repräsentation liegt nicht zuletzt

139 Vgl. hierzu Ahrens, Zu Gotha ist eine gute Kapelle (wie Anm. 7), Kap. 5, insbesondere S. 248-250.

140 Das Sächsische Feld=Lager (wie Anm. 47), S. 6.

141 Vgl. die Angaben zur Tuba curva in: Vienna Symphonic Library; http://www.vsl.co.at/ en/70/3139/3153/3154/5493.vs (Zugriff am 10. Juni 2012): „The tuba curva, a brass instrument made in Paris in 1791 for the festivities following the French Revolution, was modeled on the Roman trumpet and is regarded as a forerunner of the modern tuba. This instrument had a very powerful sound, no valves or keys and a range limited to the lowest naturals." Das bedeutete, dass lediglich der Grundton, seine Oktave und die darüber liegende Quinte, allenfalls noch die Doppeloktave des Grundtones, ausführbar waren. Siehe dazu auch Christian Ahrens, Eine Erfindung und ihre Folgen. Blechblasinstrumente mit Ventilen, Kassel u. a. 1986, S. 58 f. 
darin, dass es gleichsam idealtypisch die Vorstellungen des polnischen Königs und sächsischen Kurfürsten demonstriert. Im einschlägigen Artikel des Zedler-Lexikons heißt es nämlich: Ueberall leuchtete nebst der ungemeinen Pracht die ungemeine Klugheit Sr. Königlichen Majestät in Poblen herfür, als auf deren eigenem, bohen Angeben sich die Einrichtung des gantzen Campements eintzig und allein gründete. ${ }^{142}$

Bemerkenswert an der Dramaturgie des Campements ist, dass Theater- und Opernaufführungen (letztere am 6. und 18. Juni; Konzert am 4. Juni) ${ }^{143}$ sich zwar über den ganzen Zeitraum des Evenements verteilten, jedoch nicht dessen krönenden Abschluss bildeten. Diesem waren musikalische Aktivitäten vorbehalten, deren Wirkung weniger in ihrer musikalischen Substanz selbst als vielmehr in der beeindruckenden visuellen Großartigkeit und der exorbitanten Lautstärke lag wobei sie durch die Kombination mit dem Donner der Kanonenschüsse sowie durch die schiere Anzahl der Ausführenden (rund 350 Musiker) eindrucksvoll gesteigert wurde. So machten am 26. Juni, dem letzten Tag des Campements, die einzelnen Pelotons vor dem Zelt des preußischen Königs Front und salutierten. Der König bedankte sich bei allen Offizieren und man trank sich gegenseitig Gesundheit zu, wobei beständig die Stücken durch geschwinde Schüsse losgefeuret wurden. Weiter heißt es dann: Die sämtl. Trompeter, Paucker, Hautboisten, Tambours und Quer=Pfeiffer, wie auch Janitzscharen=Music mussten Touch darzu machen. Was dies vor Lerm untereinander war, ist mehr zu gedencken, als zu beschreiben. Denn fast 100 Trompeter, so viel [i. e. 100] Hautboisten, und mehr als soviel [i. e. mehr als 100] Tambours, wird man nicht leicht auf einem Trouppe beysammen gebört und gesehen haben. ${ }^{144}$

Dass schließlich, ganz am Ende des Campements, eine Jagd stattfand, die durch die sämmtl. Jägerey [...] mit Blasung der Waldhörner beschlossen wurde, und dass bei der Abreise des preußischen Königs wiederum die gantze Jägerey im Holtze die Wald=Hörner anstimmte, 145 beweist im Übrigen den außerordentlichen Symbolgehalt jener Instrumente. ${ }^{146}$ Mit Sicherheit war er zu dieser Zeit nicht geringer

142 Artikel: Mühlberg (wie Anm. 84), Sp. 79. Das bestätigt auch Beschorner, Zeithainer Lager (wie Anm. 91), S. 51, und hebt ausdrücklich hervor, „wie sehr der [polnische] König der eigentliche Mittelpunkt der Veranstaltungen war, in denen man mit vollem Rechte eine der grössten Veranstaltungsleistungen aller Zeiten erblickt hat." Am Campement waren übrigens ca. 30.000 Soldaten beteiligt; ebd., S. 56.

$143 \mathrm{Vgl}$. die Zusammenstellung von Beschorner, Zeithainer Lager (wie Anm. 91), S. 98 f. Für die Theater- und Opernaufführungen hatte der Architekt Matthäus Daniel Pöppelmann in Streumen eigens ein entsprechendes Gebäude errichten lassen. In der Beschreibung des Campements heißt es zur Vorstellung am 6. Juni, bei dem Musicalisch Concert [i. e. Oper] hätten sich die aus Venedig gekommene 2. Sängerinnen und 3. Castraten mit grosser Approbation hören lassen; Das Sächsische Feld=Lager (wie Anm. 47), S. 10.

144 Das Sächsische Feld=Lager (wie Anm. 47), S. 23 (Hervorhebung original).

145 Artikel Mühlberg (wie Anm. 84), Sp. 118.

146 Dem Bericht im Zedler-Lexikon zufolge (Artikel: Mühlberg (wie Anm. 84), Sp. 88) führte die Leib-Grenadier-Garde in ihrer Hautboistenformation vier Waldhornisten, 
als der der ,traditionellen' Repräsentations-Instrumente, Trompeten und Pauken. ${ }^{147}$ Das wird dadurch bestätigt, dass August der Starke für das Campement die Hautboisten der beiden Bataillone der Leibgrenadier-Garde mit silbernen Waldhörnern ausstatten ließ. Diese wurden erstmals öffentlich „beim Ausmarsche dieser ,eximierten' [d. h. direkt dem Kurfürsten unterstehenden] Truppe aus Dresden in das Lager am 15. Mai 1730“ geblasen. ${ }^{148}$

Natürlich war die besondere Hierarchie der Musikdarbietungen beim Campement wesentlich dadurch bestimmt, dass die Demonstration der majestas vorzugsweise im Freien erfolgte. Bei Festivitäten, die ausschließlich in den Räumen des Hofes oder ihm angeschlossener Säle stattfanden, bevorzugte man sicher andere Formen der Macht- und Prunkdarstellung. Aber: Das Campement war eine in jeder Beziehung herausragende Veranstaltung, zeremoniell von außerordentlicher Bedeutung, insofern galt es, alle zur Verfügung stehenden Mittel einzusetzen. Der Autor des Artikels „Mühlberg (Campement bey)“ im ZedlerLexikon stellt zu Beginn seiner Ausführungen fest, dass diese Musterung die Majestät des polnischen Königs völlig gezeiget habe, ${ }^{149}$ und liefert dann eine zwar

sechs Fagottisten und sechs Hautboisten, alle mit silbernen Instrumenten [bei den Holzblasinstrumenten vermutlich: silberne Klappen], welche unvergleichliche Music machten. Zur Funktion der Jagd im höfischen Zeremoniell siehe auch RoHR, Ceremoniel-Wissenschafft (wie Anm. 11), Kap. XIII: Von mancherley Arten der Lust=Jagten und Jagt=Divertissements, S. 859-876. Es ist sicher kein Zufall, dass von Rohr die Jagd als letztes der einzeln aufgeführten Divertissements beschreibt, bevor er im Schlusskapitel XIV: Von unterschiedenen andern Divertissements auf dem Lande, handelt. $\mathrm{Zu}$ von Rohrs Erläuterung der Jagd als Divertissement vgl. auch Stephan Selzer, Jagdszenen aus Sachsen. Die Jagd als höfisches Fest auf einem Tafelgemälde vom Ernestinischen Hof (1540), in: Gerhard Fouquet/Harm von Seggern/Gabriel Zeilinger (Hg.), Höfische Feste im Spätmittelalter (Mitteilungen der Residenzen-Kommission der Akademie der Wissenschaften zu Göttingen, Sonderheft 6), Kiel 2003, S. 73-90, hier S. 83-85; Internetversion: http://resikom.adw-goettingen.gwdg.de/MRK/SH6.htm (Zugriff am 4. September 2012). Dass bei bestimmten repräsentativen Anlässen Waldhörner den Trompeten und Pauken gleichberechtigt an die Seite treten konnten, bezeugen die Beschreibungen der Hochzeitsfeierlichkeiten in Dresden 1719. Bei der Ankunft der Braut vor dem Schloss wurde sie vom Kurfürsten und dem Erbprinzen willkommen geheißen und in die Gemächer geführt; dazu heißt es: Bey wäbrender dieser Bewillkommnung, liessen sich die Trompeten und Paucken und Waldhörner über alle massen hören [...]; Solenner Einzug der Kayserl. Ertz=Hertzogin Maria Josepha als nunmehrigen Hohen Gemahlin des Durchl. Säch. Chur=Printzens Hoheit, Friedrich Augusts, [...] Dresden o. J., S. 6.

147 Dem Bericht über das Campement im Zedler-Lexikon (Artikel: Mühlberg (wie Anm. 84), Sp. 117) lässt sich entnehmen, dass die Waldhörner bei der Jagd nicht nur eine zeremonielle, sondern auch eine funktionelle Aufgabe erfüllten: Ihr Spiel diente, ähnlich wie das Knallen der Hetz=Peitschen dazu, das Wild in die vorgesehenen Areale zu treiben, wo es dann von den Jagdherren geschossen werden konnte.

148 Neefe, Sächsische Infanteriemusik (wie Anm. 47), S. 113. Für Weimar ist belegt, dass Waldhörner mit Banderolen geschmückt oder ihre Stürzen farbig gemalt und mit dem herzoglichen Wappen in Gold verziert wurden; vgl. HStA Weimar, Fürstenhaus A 873, Schatullrechnungen 1734, fol. 73; und Fürstenhaus A 914/49, Schatullrechnungen Weihnachten 1756 bis Ostern 1757, fol. 193.

149 Artikel: Mühlberg (wie Anm. 84), Sp. 72. 
kurtze, anbey aber auch ziemlich vollständige Beschreibung, obschon bereits mehrere einschlägige Publikationen erschienen waren. Eine neuerliche Journals=Weise Darstellung hält er deswegen für geboten, weil die Sache selbst von so ausserordentlicher Erbeblichkeit gewesen sei. 150 Allein die Tatsache, dass unter bestimmten Voraussetzungen ein Musizieren der Trompeter und Pauker, der Hautboisten, der Tambours, der Quer-Pfeiffer, der Janitscharenmusiker und auch der Waldhornisten mindestens gleich viel Aufmerksamkeit erregen konnte wie eine Opern- und Ballettaufführung mit berühmten, aus Italien engagierten Sängerinnen und Sängern, zeigt, dass wir mit der Beurteilung der repräsentativen Bedeutung und Wirkung einzelner kultureller Ereignisse im Rahmen höfischer Festlichkeiten bis zum frühen 20. Jahrhundert außerordentlich vorsichtig sein und vermeiden müssen, sie mit heutigen Maßstäben zu messen. Man darf im Übrigen bei der Betrachtung derartiger Aktivitäten nicht außer Acht lassen, dass das geschilderte Spektakel beim Campement von unzähligen Zuschauern - allerdings zumeist aus größerer Entfernung - verfolgt werden konnte, dass es also dem Volk als einem der wichtigen Adressaten der Machtentfaltung möglich war, diese in jeder Beziehung außergewöhnliche Demonstration mitzuerleben. ${ }^{151}$ Das wäre weder in einem lokalen Komödienhaus noch in der Dresdner Hofoper der Fall gewesen. ${ }^{152}$ Insofern ließen sich mit dieser Freiluftveranstaltung gleich mehrere Ziele der repraesentatio majestatis erreichen: Die Präsentation - der „propren“ Soldaten, ihrer Disziplin im Hinblick auf das Einhalten der vorgegebenen Signale und Befehle (sie war auch dem als Zuschauer zugelassenen Volk am Rande des Campements vermittelbar); - der „propren“ Uniformen und übrigen Monturstücke sowie, bei der Reiterei, der Pferde (auch diese Eindrücke ließen sich allen direkt Beteiligten, aber auch dem Volk als Statist, vermitteln); - der Leistung von Küche und Keller sowie deren Personal (sie konnte lediglich von den anwesenden Exzellenzen und Bediensteten, allenfalls andeutungsweise von den gemeinen Soldaten, nicht aber vom Volk wahrgenommen werden); - Ausstattung und Leistungsfähigkeit, vornehmlich im Hinblick auf die Lautstärke, der Militärmusikformationen (diese vermochten selbst die in großer Ferne stehenden Massen zu beeindrucken).

150 Ebd.; eine Liste der Publikationen zum Zeithainer Campement findet sich bei Hans Beschorner, Beschreibungen und bildliche Darstellungen des Zeithainer Lagers, in: NASG 27 (1906), S. 103-151.

151 BesCHORNER, Zeithainer Lager (wie Anm. 91), S. 52, schreibt: „Mittlerweile aber waren auch ungezählte Fremde eingetroffen. Von fern und nah strömten die Leute herzu, hoch und niedrig, arm und reich."

152 Die Gegebenheiten der Preußischen Hofoper zu Berlin waren grundsätzlich andere: Der Bau lag außerhalb des Schlosses und die Untertanen hatten im Prinzip freien Zugang; vgl. hierzu Claudia Terne, Friedrich II. von Preußen und die Hofoper, in: Friederisiko. Friedrich der Große. Die Essays, hrsg. von der Stiftung Preußische Schlösser und Gärten Berlin-Brandenburg anlässlich der Ausstellung „Friederisiko. Friedrich der Große“ im Neuen Palais und Park Sanssouci vom 28. April bis 28. Oktober 2012, München 2012, S. 116-129, hier S. 117. 
Ob solche militärischen Demonstrationen sicheren Aufschluss über die tatsächlichen soldatischen Fähigkeiten einzelner Gruppen bzw. einer gesamten Armee geben konnten, war und ist zwar umstritten, ${ }^{153}$ aber es steht außer Frage, dass die zeremonielle Bedeutung und die Wirkung auf die Betroffenen wie auf die ,Statisten ' in der Tat außerordentlich war. ${ }^{154}$ Ursache dafür war nicht zuletzt die schiere Anzahl der Mitwirkenden, die im Hinblick auf dieses Evenement und das Ziel, einen möglichst nachhaltigen Eindruck zu erzielen, bewusst gesteigert worden war. ${ }^{155}$

\section{Schlussbetrachtungen}

Studiert man die Theoretikerschriften sowie die historischen Beschreibungen realer Veranstaltungen unvoreingenommen, dann drängt sich die Vermutung auf, dass die Wirkung zeremonieller Musik dann am größten war, wenn sie mit einer optischen Wahrnehmungs-Ebene kombiniert wurde; diese Verbindung konnte sich manifestieren in: - der Hinzufügung von Schauspiel oder Tanz, die immer auch mit der Kostümierung der Ausführenden verbunden waren; - der Hinzufügung anderer visueller Elemente, wie Livreen oder besonders ausgestatteter Musikinstrumente; - der Zurschaustellung ungewohnter bzw. neu erfundener Musikinstrumente (etwa von Glockenspielen, Waldhörnern oder dem Pantalon); - der Präsentation besonders großer Musikinstrumente (beispielsweise der gigantischen Pauken beim Campement 1730);156 - der Vergrößerung des Darbietungsapparates (z. B. durch Steigerung der Zahl der Ausführenden) - oder seine besondere Aufstellung (beispielsweise durch die Anordnung der Musiker in einer bestimmen Formation, etwa beim Aufmarsch von Soldaten, der nach geometrischen Mustern geordnet war) bzw. ihre Platzierung auf Wagen bzw. Schlitten; - der Präsentation von ungewöhnlichen Musiker-Persönlichkeiten: sei es, dass sie von besonderer Körpergröße waren (wie der finnische Paukenschläger beim Campement), ${ }^{157}$ sei es, dass es sich um Mohren handelte.

153 Vgl. Beschorner, Zeithainer Lager (wie Anm. 91), S. 81-83, der im Gegensatz zu anderen Autoren den militärischen Nutzen des Campements positiv bewertete.

154 Vgl. das oben mitgeteilte Fazit in der Beschreibung des Campements.

155 Vgl. die oben angeführte Quelle von 1692/93.

156 Ungewöhnliche Ausmaße hatte auch der am Ende des Campements aufgefahrene und unter die Offiziere und Mannschaften verteilte sogenannte Zeithainer Stollen, der rund 1,8 Tonnen wog und bei einer Länge von ca. 7 Metern eine Breite von rund 3 Metern hatte. Überdimensionierte Backwaren dienten in Kursachsen häufig als Schaustellungsund Repräsentationsobjekt der Bäckerinnungen; vgl. UlRICH Rosseaux, Freiräume. Unterhaltung, Vergnügen und Erholung in Dresden (1694-1830) (Norm und Struktur. Studien zum sozialen Wandel in Mittelalter und Früher Neuzeit 27), Köln 2007, S. $156 \mathrm{f}$.

157 Kurfürst Friedrich August I. ließ für die 1719 aufgestellte Janitscharentruppe „341 Soldaten aus seinen Regimentern auswählen, die jung, attraktiv und gleich hoch gewachsen sein sollten. Er lehnte damit den Vorschlag seiner Offiziere ab, die besonders 
Am effektivsten dürften demnach Aufführungen im Freien gewesen sein, weil dort die Menschenmenge, die man mittels des musikalischen Zeremoniells zu beeindrucken vermochte, besonders groß war. ${ }^{158}$ Auch Zeremonien in Kirchen boten den Vorteil, dass eine vergleichsweise große Zahl von Zuschauern, namentlich aus den bürgerlichen und bäuerischen Bevölkerungsschichten, angesprochen werden konnte. Konzert-, Ballett- und Opernaufführungen hingegen blieben, jedenfalls bis um 1800, überwiegend einem adligen, höfischen Publikum vorbehalten. Das Volk, das es eigentlich von der Macht des Herrschers zu überzeugen galt, hatte dort keinen Zutritt. Mit derartigen Veranstaltungen konnte zwar Eindruck „auf die sozial und politisch relevanten Beteiligten und Beobachter gemacht werden: Auswärtige Gäste und Gesandte [, die] an ihren Höfen davon berichten [sollten]“; die Untertanen jedoch vermochten als Statisten keine Rolle zu spielen. Damit blieb ein bedeutender Teil des Zeremoniells letztlich in seiner Wirkung wesentlich eingeschränkt. ${ }^{159}$

Zusammenfassend lässt sich festhalten:

1. Die musikalische repraesentatio majestatis konnte sich gewissermaßen auf zwei Ebenen vollziehen. Einmal auf der der ,Eigeninitiative', d. h. veranlasst, organisiert und verantwortet vom Herrscher selbst. Dann aber auch auf der der Entgegennahme von Huldigungen, die von einer Gruppe der Untertanen oder - wie etwa in den geschilderten Fällen aus Weimar - von der Einwohnerschaft der Residenz und ihren Repräsentanten dargebracht wurden. Ob und gegebenenfalls in welchem Ausmaß im letzteren Falle die Hofverwaltung eine zeremonielle Richtschnur vorgab, lässt sich heute nicht mehr feststellen. Nötig gewesen wäre sie vermutlich nicht, weil das Repertoire an einschlägigen Symbolen, Handlungen und Aktivitäten den Untertanen natürlich vertraut war.

2. Die Mittel und die Symbole repräsentativer musikalischer Aktionen waren außerordentlich vielfältig. Dabei konzentrierte sich das Repertoire keineswegs auf

mutige und verdienstvolle Soldaten für die Jantischarengarde geeigneter hielten.“; Elisabeth Hackspiel-Mikosch, Vorläufer der zivilen Uniformen im 18. Jahrhundert. Hofmonturen als Inszenierung fürstlicher Macht im höfischen Fest, in: Dies./Stefan Haas (Hg.), Die zivile Uniform als symbolische Kommunikation (Studien zur Geschichte des Alltags 24), Stuttgart 2006, S. 47-79, hier S. 53 f.

158 Wie bedeutsam die Masse der Beteiligten für jedwede Repräsentation von Macht war, erhellt beispielsweise aus den Worten von Wolffs: Bey Auswärtigen dependiret das Ansehen der Landes=Obrigkeit nicht davon, ob ibre Macht und Gewalt uneingeschränkt ist, oder nicht, sondern vielmehr von der Grösse der Macht. Wer viel Geld und Volck zusammen bringen kan, wenn es die Noth erfordert, der hat das gröste Anseben; WolfF, Vernünfftige Gedancken (wie Anm. 3), \$ 449, S. 483). Vgl. beispielsweise Lünings Beschreibung der Festivitäten bei den Friedens=Banquets während des Nürnberger Exekutionstages am 4. und 14. Juni 1650 vor der Stadt Nürnberg auf dem Schieß=Platz; Lüning, Theatrum Ceremoniale Politicum (wie Anm. 30), Bd. 1, S. 824-828.

159 Die Einbeziehung der Bevölkerung in repräsentative höfische Zeremonien stellt Rosseaux, Freiräume (wie Anm. 156) als bedeutsame Errungenschaft des augusteischen Zeitalters heraus. 
die bislang in der Forschung bevorzugt diskutierten Gattungen - Oper und Ballett; Konzert -, Orte bzw. Räumlichkeiten - Opernhaus bzw. Theater, Prunkoder Konzertsaal - sowie die Gruppe der Trompeter und Pauker mit ihren spezifischen Instrumenten und nicht zuletzt bestimmte, vom Herrscher definierte bzw. ad hoc festgesetzte Anlässe. Vielmehr konnten durchaus andere Gattungen bedeutsam sein: etwa die Militärmusik; andere Räumlichkeiten: beispielsweise die Kirche, das Exerzierfeld oder Straßen und Plätze einer Residenzstadt; andere Instrumente: u. a. jene der Janitscharenmusik oder die bei der Jagd geblasenen Waldhörner; andere Anlässe: beispielsweise ein militärisches oder ziviles Lustlager oder die An- oder Abreise eines Fürsten.

3. Im Zentrum der repraesentatio stand nicht das Musizieren im engeren Sinne, sondern eher das symbolhafte Lärmen. Es ging vornehmlich um Lautstärke dafür waren besonders große Musikergruppen oder beispielsweise riesige Pauken hervorragend geeignet, was zugleich die optische Wirkung beträchtlich steigerte-, nicht um eine besonders hohe musikalische Kunstfertigkeit. Welche Bedeutung dem Lärm bei derartigen Repräsentations-Veranstaltungen zugemessen wurde, belegt nicht zuletzt das Einbeziehen von Geschützen und von Glocken in die zeremonielle Verherrlichung der majestas durch Musik.

4. Für repräsentative Veranstaltungen wurden bei entsprechendem Bedarf nicht nur alle zur Verfügung stehenden Mittel eingesetzt, sondern auch alle zum Musizieren geeigneten Personen. Dabei konnten Gruppierungen gemeinsam in Aktion treten, die in der Regel getrennt musizierten, etwa Trompeter und Pauker mit den Hautboisten und sogar den Stadtmusikern, oder eine Formation die Funktion einer anderen übernehmen. Die Behauptung, die Privilegien hätten ein Zusammenwirken der Trompeter mit anderen Musikern grundsätzlich verboten, hält einer Nachprüfung nicht stand. 160 Allerdings wurden die Bestimmungen auf der Basis sogenannter Observanzen regional sehr unterschiedlich ausgelegt. So geht aus einem Schreiben der Münchner Hoftrompeter von 1793 hervor, dass sie bei Gelegenheit des Einzuges des bayerischen Kurfürsten in die Residenzstadt zur Verstärkung ihrer Truppe nicht etwa Stadtmusiker herangezogen hatten, sondern nach Erforderniß der Privilegien gelernte Trompeter u. Panker aus Augsburg und Freising. ${ }^{161}$ Ein Beispiel für eine besonders weitherzige Interpretation der Privilegien liefert hingegen der Weimarer Hof. Dort wurde in den 1780er-Jahren der Stadtmusikus angewiesen, mit seinen Leuten nicht nur die Hofkapelle zu verstärken, sondern auch in der Oper die gegebenenfalls anfallende Bühnenmusik auszuführen. Zudem musste er bei Hof Ballen, beÿ Jagden, [...] [und] auch wenn

160 Johann Ernst Altenburg, Anleitung zur heroisch-musikalischen Trompeter- und Pauker-Kunst [...], Halle 1795, S. 23; vgl. auch Christoph-Hellmut Mahling, Münchener Hoftrompeter und Stadtmusikanten im späten 18. Jahrhundert, in: Zeitschrift für Bayerische Landesgeschichte 31 (1968), S. 649-670, hier S. 651, der sich auf die entsprechende Passage von Altenburg bezieht.

161 Zitiert nach: Mahling, Hoftrompeter und Stadtmusikanten (wie Anm. 160), Eingabe der Hoftrompeter, S. 661-666, hier S. 665. 
Serenissimus oder der Hof beÿ anderen nicht vorauszusehenden Vorfallenheiten benötlich seÿn sollten zu Diensten sein. ${ }^{162}$ Damit trat die Stadtmusik den übrigen musikalischen Formationen am Hof zu bestimmten Anlässen gleichberechtigt an die Seite. ${ }^{163}$ Diese strukturellen Besonderheiten der Weimarer Hofoper bestärken die Zweifel daran, dass die Oper generell als das herausgehobene exklusive Symbol der musikalischen repraesentatio majestatis anzusehen ist, wie es Henze-Döhring mit ihrer Formulierung von der „,Majestät‘ unter den musikalischen Gattungen“164 suggeriert. Dass aufwendige theatralische Spektakel mit Musik, und gerade nicht die Oper, oftmals wesentlich mehr Eindruck machen konnten, beweisen die Aktivitäten anlässlich des Besuchs des dänischen Königs Frederik IV. im Juni 1709 in Dresden. Die brillante Aufführung von „Le Théâtre des plaisirs“ - die größte repräsentative theatralische Veranstaltung seit Friedrich Augusts I. Thronbesteigung 1694, die in sich unterschiedlichste künstlerische Gattungen, darunter ganz selbstverständlich auch Gesangseinlagen und ein Ballett, vereinte -, charakterisiert Helen Watanabe-O'Kelly folgendermaßen: „This is pure entertainment, a visual show without any intellectual or political content." 165

5. Lars E. Laubhold ${ }^{166}$ fasste die besondere zeremonielle Bedeutung des Trompeter- und Paukercorps in der Formulierung zusammen, es künde nicht nur von der Macht eines Fürsten, sondern es vermöge sogar, sie zu generieren. Die oben angeführten Beispiele belegen, dass es nicht grundsätzlich um das Ensemble selbst ging (also die Formation der privilegierten Trompeter und Pauker am Hof), sondern vornehmlich um das Instrumentarium und die auf ihm ausgeführte spe-

162 HStA Weimar, Hofmarschallamt Nr. 2588, Acta die Redouten betr. Ao 1775, fol. 35r/v, Datum des Erlasses: 4. Dezember 1786. Die Regelung war de facto bereits einige Jahre früher in Kraft getreten. Der Stadtmusikus Alexander Bartholomäus Eberwein (17511811) erhielt für diese Dienstleistungen den „Character“ eines Hofmusikus' und ein Salär von 150 Thlr. im Jahr.

163 Dass in Weimar das Musizieren der Stadtmusiker mit Mitgliedern anderer Gruppen bei zeremoniellen Anlässen möglich war und praktiziert wurde, ist einigermaßen erstaunlich: Beim Zusammenwirken der Stadtmusiker mit der Hofkapelle kam es immer wieder zu Streitigkeiten und erheblichen Irritationen. Das Klima unter den Musikern war über Jahrzehnte hinweg bis ins erste Drittel des 19. Jahrhunderts hinein ausgesprochen schlecht.

164 Henze-Döhring, Musik im höfischen Zeremoniell (wie Anm. 4), S. 31.

165 Helen Watanabe-O`Kelly, Court Culture in Dresden. From Renaissance to Baroque, Houndmills 2002, S. 208 f. Diese Gesetzmäßigkeiten galten im Grundsatz auch für andere Hofhaltungen. Am preußischen Hof beispielsweise trat die Wirkung von Musik und Schauspiel in der Oper während der Regierungszeit Friedrichs II. zurück hinter der optischen Erscheinung des Herrschers. Denn der König nahm nicht in der zentralen Mittelloge des ersten Ranges Platz (dort saßen die übrigen Mitglieder der königlichen Familie), sondern auf einem Sessel in unmittelbarer Nähe des Orchesters, hinter dem Kapellmeister. „Von dieser Position aus wurde er als höchster Repräsentant des Staates und der Kultur nicht nur besser gesehen als in der Loge, er selbst konnte das Bühnengeschehen auch besser kontrollieren."; Terne, Friedrich II. (wie Anm. 152), S. 119.

$166 \mathrm{Vgl}$. weiter oben. 
zifische Musik. Wurde diese Aufgabe anderen Musikergruppen übertragen, dann konnten diese in gleicher Weise repräsentativ agieren wie die Hoftrompeter.

6. Was für die musikalisch-emblematische Funktion von Trompetern und Paukern gilt, trifft auch auf ihre Instrumente zu. Die Vorstellung, deren besonders aufwendige Faktur sei ein Alleinstellungsmerkmal dieser Formation, lässt sich nicht halten. In bestimmten Kontexten und historischen Zusammenhängen konnten auch andere Instrumente durch eine besonders kostbare äußere Gestaltung in ihrer emblematischen Bedeutung gesteigert werden. ${ }^{167}$

7. Die angeführten Beispiele belegen, dass es zwar Grundmuster der Zelebrierung von Herrschaftsmacht durch musikalische Aktivitäten gab, dass aber von einem einheitlichen Verfahren an allen Höfen, wie Maria Richter zu Recht konstatierte, keine Rede sein kann: „Damit bestätigen sich auch die eingangs genannten Zweifel, ob das Phänomen Hofmusik so abstrahiert werden darf, dass es - nach allgemeinen, zeremoniellen Mustern funktionierte, die völlig unabhängig vom jeweiligen Ort an allen Höfen Wirkung zeigten - überall gleich ablief. Denn gerade die politischen Verhältnisse waren doch von Hof zu Hof sehr unterschiedlich, vor allem in den Sekundärfürstentümern, wo mit der Primogenitur eine zusätzliche Macht von außen das Hofleben beeinflusste." 168 Allerdings ist die Verschiedenheit der Machtdemonstration sicher nicht allein den von der Autorin benannten Unterschieden in den politischen Verhältnissen geschuldet. Vielmehr hatte der jeweilige Herrscher die Freiheit, aus dem Kanon der Zeremonalien jene auszuwählen, die seinen eigenen Intentionen und den äußeren Bedingungen - wohl auch bestimmten lokalen Traditionen, Vorstellungen der Untertanen oder speziellen Vorlieben auswärtiger Gäste - sowie den daraus resultierenden politischen Zwängen am besten entsprachen. So nahm beispielsweise August der Starke nach den Erfahrungen während des Besuchs des preußischen Königs Friedrich Wilhelm I. (1688-1740) in Dresden 1728 zwei Jahre später beim Campement stärker auf die spezifischen Interessen seines königlichen Gastes Rücksicht, was dessen begeisterte Reaktion auf das militärische Spektakel erklärt. ${ }^{169}$ Dass es den Potentaten

167 Vgl. die Angaben zu den Instrumenten der Hautboisten beim Campement von 1730. Dass auch musikalisch weniger bedeutsame Instrumente als Trompeten und Pauken zum Zwecke einer größeren repräsentativen Wirkung in ungewöhnlicher Weise verziert wurden, lässt sich dem Bericht über die Feierlichkeiten zum Einzug des damaligen sächsischen Kurprinzen und seiner Gemahlin 1719 in Dresden entnehmen. Dem Festzug voran ritt der General-Postmeister und Kammerherr Baron von Morday. Er führte an einer mit Gold und Silber melirten Schnur und Quaste ein massiv goldenes Posthorn so mit Edelsteinen versetzet; Accurate Beschreibung (wie Anm. 62), S. 6.

168 Maria Richter, Hofmusik in Sachsen-Merseburg. Historische Zusammenhänge zwischen Musik und Politik am Beispiel der Hofkapelle, in: Vincenz Czech (Hg.), Fürsten ohne Land. Höfische Pracht in den sächsischen Sekundogenituren Weißenfels, Merseburg und Zeitz (Schriften zur Residenzkultur 5), Berlin 2009, S. 325-348, hier S. 348 .

169 August der Starke hatte dem preußischen König bei dessen Besuch in Dresden 1728 vornehmlich „Gastereien, Theatervorstellungen, Feuerwerke und Bälle“ präsentiert, Divertissements also, die dieser nicht sonderlich goutierte; vgl. Beschorner, Zeit- 
weitgehend frei stand $\mathrm{zu}$ entscheiden, welcher repräsentativen Mittel sie sich bedienen wollten, hatte bereits Johann Christian Lüning herausgestellt: [...] doch bleibet einem jeden regierenden Herren dabey unbenommen, wie alle solche Reglements überbaupt zu ändern, also auch diese solenne Actus nach Bewandniß der Zeit, Orts, Personen, Casse etc. prächtiger oder geringer anzustellen. Und eben also verbält es sich auch, wenn grosse Herren die Regierungen antreten, oder quittiren, zu successoren beruffen, erweblet, oder gecrönet werden; denn da hat ein jeder solcher solennen Actus sein besondres Reglement, doch stebet es sodann in eines jeden grossen Herren Willkühr demselben nachzufolgen oder nicht, auch die Solennitäten bey solchen Actibus propre oder geringe, nach Bewandniß der Umstände, anzuordnen. [...] Doch alle dergleichen Anordnungen im Ceremonien= Wesen zu machen, fallen einem Soiuverain gar leicht; weil sie lediglich von seiner Willkür dependiren. ${ }^{170}$

8. Festzuhalten gilt schließlich, dass bestimmte musikalische Traditionen der repraesentatio majestatis nicht im Zuge einer sich wandelnden Musikästhetik und -praxis aufgegeben oder angepasst wurden, sondern dass man sie bis zur Auflösung der Monarchie in Deutschland weitgehend unverändert bewahrte. ${ }^{171}$ Das bedeutete, wie sich am Beispiel der Dresdner Hoftrompeter zeigen lässt, dass dieser Bereich des ,Musizierens' von der allgemeinen Entwicklung der Musik abgekoppelt war. Und zwar sowohl im Hinblick auf die Instrumente (Naturtrompeten) als auch die Musik, die wegen der Beschränkungen des Tonvorrats nach wie vor nicht anders als fanfarenartig klingen konnte. Die musikalischen Darbietungen im Rahmen der repraesentatio majestatis bewegten sich in einem merkwürdigen Spannungsfeld von Tradition und Anpassung. Oper und Konzert etwa folgten dem Wandel der Ästhetik nicht nur stilistisch, sondern auch im Hinblick auf die Steigerung der Kunstfertigkeit in der Ausführung und deren Perfektion. ${ }^{172}$

hainer Lager (wie Anm. 91), S. 81. Allerdings steht außer Frage, dass der damalige Kronprinz Friedrich, der den König begleitete, von vielen dieser Darbietungen, namentlich denen in der Oper, tief beeindruckt war und wesentliche Impulse für seine eigenen kulturellen Aktivitäten empfing; vgl. Louis SchneIder, Geschichte der Oper und des Königlichen Opernhauses in Berlin, Berlin 1852, S. 46-49.

170 LüNING, Theatrum Ceremoniale Politicum (wie Anm. 30), Bd. 1, S. 3.

171 Bis heute wird in Frankreich zu Repräsentationszwecken die Garde Républicaine zu Pferde in ,historischen“ Uniformen eingesetzt, ihre „Fanfare“ musiziert, unterstützt von Paukern, auf Naturtrompeten.

172 Ausnahmen gibt es freilich auch hier. Georg Friedrich Händel (1685-1759) beispielsweise hat im Dramma per Musica Agrippina (1709) und in der Oper Rinaldo (1711) beides Werke mit dezidiert repräsentativem Charakter - nicht notierte Trompetenpartien vorgeschrieben; in Rinaldo steht an der entsprechenden Stelle zu Beginn der 2. Szene des 1. Aktes: S'oda suonar una tromba, che precede un'Araldo speditto dalla città; vgl. dazu auch Dirk Möller, Besetzung und Instrumentation in den Opern GeorgFriedrichHändels(EuropäischeHochschulschriften, Reihe36: Musikwissenschaft 38), S. 76 f. Damit übergab der Komponist seine Kompetenz gleichsam an den ausführenden Trompeter, der eine traditionelle Aufzugsmusik ausführte, die ohne direkten musikalischen Bezug zum Kontext war und auf die Händel keinen Einfluß hatte. Im Vordergrund der repräsentativen Wirkung stand die Person des in offizieller Mission 
Das trifft in vergleichbarer Weise für Teile der Militärmusik zu, die sich den Normen des Musizierens im zivilen Bereich weitestgehend anpassten. Es galt hingegen z. B. nicht für die Militär- und Kirchenmusik in ihrer ausschließlich repräsentativen Funktion, und offenbar gerade nicht für den emblematischen Einsatz des Trompeter- und Paukercorps, das sich jedenfalls am königlich-sächsischen Hof in Dresden noch zu Beginn des 20. Jahrhunderts kaum anders artikulierte als in den vorangegangenen Jahrhunderten. ${ }^{173}$ Insofern lässt sich die These von HenzeDöhring, die Entwicklung zu einem Höchstmaß an künstlerischer Qualität in der Ausführung von Musik als Mittel der Machtdemonstration habe dazu geführt, dass die „einst würdigste Zunft der Trompeter“ nach und nach der Bedeutungslosigkeit anheimgefallen sei, ${ }^{174}$ keineswegs auf alle Höfe übertragen; gerade für Dresden trifft sie nicht zu. Diese teilweise Abkoppelung musikalischer Repräsentationsmusik von den übrigen künstlerisch-ästhetischen Entwicklungsprozessen $^{175}$ widerspricht in bemerkenswerter Weise den gesellschaftspolitischen Veränderungen, die auf dem Gebiet der Literatur in Weimar bereits um 1800 begannen und zu einer Emanzipation der Kultur „aus der Rolle einer bloßen Repräsentationskulisse“ hin zu einer „Art Partnerschaft“ zwischen den Regenten und den am Hof versammelten Künstlern führten. ${ }^{176}$ Im Bereich der zeremoniellen Musikausübung verblieben die Massen in ihrer Statistenrolle, sie bildeten nach

auftretenden Herolds - mit entsprechendem Habit -, dem ein Trompeter voranschritt, der die vorgeschriebenen, für jeden Zuhörer erkenn- und dechiffrierbaren Signale ausführte. Derartige repräsentativ-emblematischen Partien stehen in gewisser Weise außerhalb des musikalischen Kontextes einer Oper und ihres ästhetischen Anspruchs.

173 Vgl. hierzu Ahrens, Intraden, Trillos und Aufzüge (wie Anm. 41), S. 67 f. Die Dresdner Hoftrompeter trugen bis 1918 eine historisierende Uniform und musizierten bei ihren dienstlichen Obliegenheiten auf Naturtrompeten, obschon sie spätestens seit Mitte des 19. Jahrhunderts ausnahmslos das Spiel von Ventiltrompeten beherrschten und somit in der Lage waren, in einem Orchester mitzuwirken. Dass auch am Kaiserhof in Wien während der Hochblüte der Clarinblaskunst in der ersten Hälfte des 18. Jahrhunderts neben Opern, die zur Demonstration der Virtuosität der Trompeter extreme Clarinpartien enthalten, $z u$ repräsentativen $Z$ wecken andere Musikgattungen entstanden, die von überkommenen Techniken einer „,improvisierten Trompetenmusik“ bestimmt wurden, hat Detlef Altenburg am Beispiel der Werke von Johann Joseph Fux (1660-1741) verdeutlicht; Altenburg, Instrumentation im Zeichen des Hofzeremoniells (wie Anm. 37), S. 167 f. Die Spannweite der musikalischen Struktur in den verschiedenen Fuxschen Trompetenpartien zur repraesentatio majestatis ist extrem groß und lässt sich sicher mit der zuvor geschilderten in der repräsentativen Musik des 19. Jahrhunderts (Naturtrompeten versus Ventiltrompeten) vergleichen.

174 Henze-DöHring, Musik im höfischen Zeremoniell (wie Anm. 4), S. 32. Die Verfasserin stützt sich bei ihrer Aussage auf Altenburg, Geschichte der Trompete (wie Anm. 19), Bd. 1, S. 27 f.

175 Vgl. hierzu beispielhaft Konrad Neefe, Die geschichtliche Entwicklung des Signalwesens bei der Kur= und Königl. Sächs. Reiterei, in: Der Kamerad 33; Nr. 5, S. 2 f.; Nr. 6, S. 2-4; Nr. 7, S. 4-6; Nr. 8, S. 2-4; Nr. 9, S. 3-5; Nr. 10, S. 3 f.; Nr. 11, S. 3 f., hier insbesondere den Schlussteil des Artikels.

176 Gerhard Müller, Kultur als Politik in Sachsen-Weimar-Eisenach, in: Lothar Ehrlich/ Georg Schmidt (Hg.), Ereignis Weimar-Jena. Gesellschaft und Kultur um 1800 im internationalen Kontext, Köln u. a. 2008, S. 67-83, hier S. 70. 
wie vor eine „bloße Repräsentationskulisse“..177 Und auch jene Wirkmechanismen, die Gerhard Müller für das Verhältnis von Kultur und Staatspolitik in Weimar Anfang des 19. Jahrhunderts herausgearbeitet hat, galten für Musik im Rahmen der repraesentatio majestatis nicht: Musikdarbietungen mussten weiterhin den tradierten Handlungs- und Darstellungsmaximen eines feudalen Staatswesens entsprechen. ${ }^{178}$ Obschon die „überkommenen politischen Strukturen“ wegbrachen, ${ }^{179}$ wirkten deren symbolhafte Prinzipien der Außendarstellung im musikalischen Bereich weiter und zeigten eine bemerkenswerte Konstanz.

Mit Bezug auf Gottfried Stieves ${ }^{180}$ Ansichten über die majestas von Fürstentümern im Vergleich zu der von Republiken hatte Juliane Riepe formuliert:181 „Majestät, die man nicht sehen kann, ist keine Majestät oder hat doch jedenfalls der zu weichen, die vor aller Augen ist", und daran die provokante Frage geknüpft, wie sich Musik und Zeremoniell zueinander verhielten und ob man Macht auch hören können müsse. Eigentlich hätte ihre Frage lauten müssen, ob Majestät - die nach übereinstimmender Auffassung der Theoretiker des 17. und 18. Jahrhunderts visuell wahrgenommen werden musste - überhaupt ausschließlich hörend vermittelt werden könne. Die hier vorgestellten Beispiele belegen jedenfalls eine Tendenz, die Wirkung von Musik im Rahmen der repraesentatio majestatis dadurch abzusichern bzw. zu verstärken, dass den Zuschauern zusätzlich eine optische Ebene präsentiert wurde: z. B. durch die Pracht, die Größe oder die Exotik der Instrumente; durch die Kostbarkeit der Musiker-Livreen und Accessoires; durch die Zahl der beteiligten Musiker oder ihre Hautfarbe, Körpergröße etc. Und schließlich auch durch die Lautstärke der dargebotenen Musik, die notfalls durch hinzutretende Lärmquellen gesteigert werden konnte. All diese uns heute befremdlich und übertrieben anmutenden Staffagen, die visuellen Besonderheiten, wie sie geradezu idealtypisch in den musikalischen Aktivitäten während des Campements von 1730 zum Ausdruck kamen, lassen nur einen Schluss zu: Da man im Hinblick auf die Repräsentation der majestas sich nicht allein auf den ,normalen“ musikalisch-akustischen Eindruck verlassen zu können glaubte, musste man ihn künstlich verstärken und durch optische Wahrnehmungen unterstützen.

177 Karlheinz Blaschke, Hof und Hofgesellschaft im Königreich Sachsen während des 19. Jahrhunderts, in: Dresdner Hefte 21 (1990), S. 60-67, hier S. 60, konnte zeigen, dass diese Konstanz über Zeiten und Epochen hinweg ein Wesensmerkmal des sächsischen Hofstaats war. Insofern fügt sich die musikalische repraesentatio majestatis in ein Gesamtkonzept ein.

178 MüLler, Kultur als Politik (wie Anm. 176), S. 67; vgl. auch ebd., S. 70.

179 Ebd., S. 80; vgl. auch die Ausführungen S. 79-81.

180 GotTfried Stieve, Europäisches Hof=Ceremonial, in welchem Nachricht gegeben wird, was es für eine Beschaffenheit habe mit der Praerogativa und dem aus selbiger fliessenden Ceremoniel, welches zwischen Kayser= und Königl. Majestäten, Churfürsten, Cardinälen, Fürsten und freyen Republiquen, deren Gesandten und Abgesandten beobachtet wird [...], Leipzig 1715 .

181 RiEPE, Hofmusik in der Zeremonialwissenschaft (wie Anm. 1), S. 27. 
Für den Dresdner Hof hatte Sabine Henze-Döhring die These formuliert, dass mit Einleitung einer organisatorischen Reform bei Regierungsantritt des Kurfürsten Friedrich August II. (1696-1763; reg. 1733-1763) der „höfische Repräsentationscharakter der Musik“ sich grundlegend gewandelt habe: „Die zeremonielle Bedeutung von Musikern und Musik als Symbolträgern oder Mittlern dynastischer Hierarchien und Botschaften wich der Vorstellung, daß einzig und allein die Produktqualität musikalischer Kunstereignisse für die höfische Repräsentation als ausschlaggebend anzusehen sei. “182

Es mag heute schwer vorstellbar sein, aber die Quellen belegen zweifelsfrei, dass in jenem Prozess der musikalischen Vermittlung von herrschaftlicher Erhabenheit die Kunstfertigkeit der Musiker und die Perfektion der von ihnen produzierten Musik zwar wesentliche Faktoren waren, jedoch keineswegs die einzigen und im Bewusstsein aller Beteiligten bis weit ins 19. und teilweise bis ins 20. Jahrhundert hinein offenkundig auch nicht die entscheidenden. ${ }^{183}$ Von essenzieller Bedeutung für jegliche repräsentative musikalische Darbietung waren hingegen optische Elemente, ohne die die Musik ihre Wirkung auf das Publikum nicht oder nur unvollkommen hätte entfalten können - daran lassen die Formulierungen in der oben zitierten Beschreibung des Campements von 1730 sowie die Äußerungen Christian Freiherr von Wolffs ${ }^{184}$ keinen Zweifel. Vermutlich ohne sich darüber Rechenschaft abzulegen, postulierte der Autor damit eine wichtige Maxime musikalischer Wahrnehmung durch breite Bevölkerungskreise. Poetisch überhöht und auf den christlichen Glauben bezogen, hatte der Dichter Barthold Heinrich

182 Henze-Döhring, Musik im höfischen Zeremoniell (wie Anm. 4), S. 32. Die Reform bestand darin, dass die Zuständigkeit für die Hofkapelle vom Oberhofmarschallamt auf die Hofkämmerei übertragen wurde. Die Trompeter und Pauker blieben weiterhin dem Oberhofmarschall unterstellt. Dass diese generalisierende These von Henze-Döhring auch für den Wiener Kaiserhof keine Gültigkeit beanspruchen kann, ergibt sich aus den Darlegungen von Detlef Altenburg zur höfisch-repräsentativen Musik von Johann Joseph Fux; Altenburg, Instrumentation im Zeichen des Hofzeremoniells (wie Anm. 36).

183 Bis zum Ende der Monarchie war das musikalische Leistungsniveau der Dresdner Hoftrompeter, wie bereits erwähnt, deutlich geringer als das ihrer Kollegen in der Kapelle. Für ihren Dienst als Hoftrompeter mit fast ausschließlich zeremonieller Funktion (so mussten sie beispielsweise die Honoratioren zu Veranstaltungen am Hofe laden; ihre Aufgaben wurden in einem Anstellungsvertrag von 1914 mit Ansagen, Einladungen und Ausrichtungen umschrieben; vgl. hierzu AHrens, Hautboisten versus Trompeter (wie Anm. 70), S. 54-56) reichten ihre oft nur mittelmäßigen musikalischen Kenntnisse und Fertigkeiten, nach Auffassung der Kapellmeister, die die Stellenbewerber zu beurteilen hatten, jedoch aus. Vgl. dazu Ahrens, Intraden, Trillos und Aufzüge (wie Anm. 41), S. 61-63. Im Übrigen ist weder in den Trompeter-Privilegien, noch in der einschlägigen zeitgenössischen Literatur zum Zeremonialwesen von der musikalischen Leistungsfähigkeit der Trompeter bei Erfüllung ihrer repräsentativen Funktion die Rede.

184 Vgl. Anm. 5. 
Brockes (1680-1747) im zweiten Teil seines Irdischen Vergnügens in Gott (1724) ein ähnliches Gleichnis formuliert. So verwirrend dessen vermeintliche Paradoxie heute wirken mag - es lässt sich uneingeschränkt und mit vollem Recht auf die repraesentatio majestatis durch Musik übertragen: Meine Seele hört im Seben $[\ldots] \cdot{ }^{185}$

185 So der Textbeginn einer jener Arien (HWV 207; ca. 1725) von Georg Friedrich Händel, die in dem Sammelwerk „Neun deutsche Arien“ zusammengefasst sind. 